\title{
Partial reactivation of a huge deep-seated ancient rock slide: recognition, formation mechanism, and stability
}

\author{
Minggao Tang ${ }^{1,2}$, Qiang Xu${ }^{1}$, Yusheng Li $^{2}$, Runqiu Huang ${ }^{1}$, Niek Rengers ${ }^{1, a,{ }^{*}}$, and Xing Zhu ${ }^{1}$ \\ ${ }^{1}$ State Key Laboratory of Geohazard Prevention and Geoenvironment Protection (Chengdu University of Technology), \\ Chengdu, 610059, China \\ ${ }^{2}$ College of Environment and Civil Engineering, Chengdu University of Technology, Chengdu, 610059, China \\ ${ }^{\text {a }}$ formerly at Faculty of Geo-Information Science and Earth Observation, University of Twente, \\ 7500 AE Enschede, the Netherlands \\ *retired \\ Correspondence to: Qiang Xu (xq@cdut.edu.cn)
}

Received: 17 September 2015 - Published in Nat. Hazards Earth Syst. Sci. Discuss.: 5 November 2015

Revised: 19 May 2016 - Accepted: 3 July 2016 - Published: 1 August 2016

\begin{abstract}
About 18 years ago, a large-scale discontinuous layer in properties and colour was found in the new Fengjie town at the shore of the Three Gorges Reservoir area in China. There are many resettled residents and buildings on the sloping area, the safety of which is potentially affected by this layer, so it has become the focus of attention. Before this study started there were two viewpoints regarding the origin of this layer. One was that is was from a huge ancient slide and the other was that is was from a fault graben. In order to find out how it was formed and to be able to carry out a stability analysis of the slope the authors have carried out a research program, including geological field investigations and mapping, a deep drilling hole, a geotechnical centrifuge model test, and a simulation analysis. The results of the research led to the conclusion that the layer is the sliding plane of a huge deep-seated ancient rock slide, which we called the Sanmashan landslide. An important argument for the conclusion is the recognition of a regional compressive tectonic stress field in this area, which cannot lead to the formation of a fault graben because it needs a tensional tectonic stress field. Moreover, numerous unique geological features, sliding marks, and other relics of the ancient slide have been discovered in the field. The formation process of the ancient slide could be repeated in a large geotechnical centrifuge model test. The test shows that a deformation and failure process of "creep-crack-cut" has occurred. The type of the ancient slide can be classified as a "successive rotational rock slide". Finally, the role of seepage in the stability
\end{abstract}

of the Sanmashan landslide has been analysed. Our final conclusions are that, during rainfall and filling-drawdown cycles in the Three Gorges Reservoir, the Sanmashan landslide as a whole is dormant and stable and the secondary landslides in the toe area of the slope are presently stable but can be reactivated. This research provides an important basis for the remedial measures and land use planning in the new Fengjie town, and a well-documented case history for researchers worldwide.

\section{Introduction}

Before the old town of Fengjie was submerged in the water of the Three Gorges Reservoir, the Sanmashan slope area was recommended as the resettlement site for building a new Fengjie in 1997 (Fig. 1). During the construction process of the new Fengjie town, a large-scale discontinuous weak zone was found in the Sanmashan slope area in 1998 (Fig. 2). To determine the safety of the slope by geotechnical analysis, it was necessary to determine the origin and characteristics of the weak zone.

The identification and formation mechanism of deepseated ancient rock slides is an important research subject (Crosta, 1996; Crosta and Zanchi, 2000). It is well known that both a rock slide and tectonic faulting can form an important weak zone (Illies, 1981; Chang et al., 1981; Crosta, 1996; Crosta and Zanchi, 2000; Cruden and Martin, 2007; 


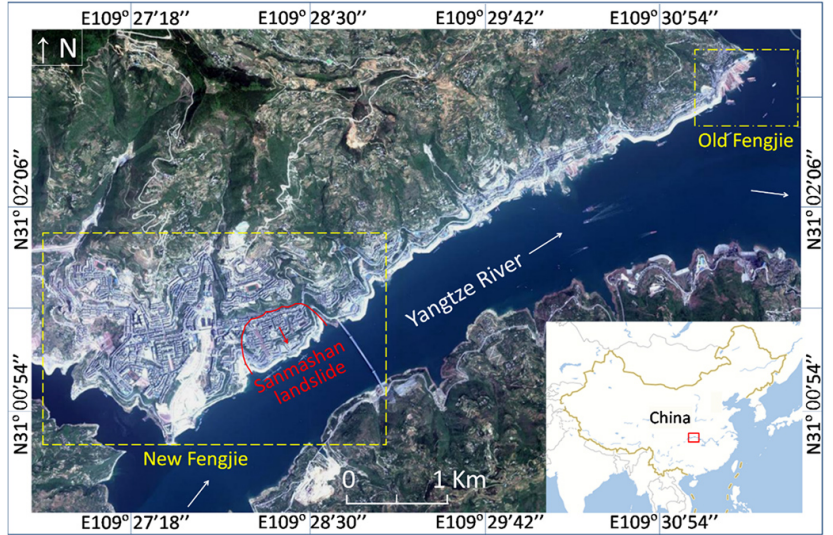

Figure 1. Location map of the Sanmashan landslide $\left(31^{\circ} 01^{\prime} 18^{\prime \prime} \mathrm{N}\right.$, $109^{\circ} 28^{\prime} 16^{\prime \prime} \mathrm{E}$ ) (Quickbird image, 2 May 2010). It is located in the new Fengjie town in the Three Gorges Reservoir area, Chongqing, China. The old Fengjie town was submerged after the Three Gorges Reservoir filled with water in 2003.

John and Douglas, 2012). However it is often not easy to decide which process has taken place. Michael et al. (2012) found that a landslide scarp can easily be misinterpreted as a fault. However, tectonic activity can play a key role in the development of a large-scale rock slide (Brideau et al., 2009). In this paper we describe the study of a very large, interesting deep-seated rock slide, called the Sanmasan landslide, in the new Fengjie town of the Three Gorges Reservoir area, Chongqing, China (Figs. 1 and 2).

Before the start of our research there were two viewpoints or hypotheses about the origin of the weak zone: a huge ancient slide or a fault graben. Some authors (BIS-CWRC, 1997, 1999) suggested that it was caused by geological tectonic activity, as the slope area is surrounded by four normal faults (see Supplement 1, from the previous study), due to the formation of a local fault graben, and this viewpoint was quoted in later research papers ( $\mathrm{Li}$ et al., 2002; Wang et al., 2006; Qi et al., 2012). Other authors (Nanjiang Geological Team, 1999) speculated that the weak zone was the result of a very large ancient rock slide. These two different viewpoints confused the land use planners and those responsible for geological hazard prevention in the new Fengjie town. A large number of resettlemed residents and buildings on the Sanmashan area were located in the new Fengjie town (Fig. 3), and filling-drawdown cycles of the reservoir water table and rainfall may affect the stability of the landslide with disastrous consequences (Alonso and Pinyol, 2010; Barla et al., 2010; Paronuzzi et al., 2013; Tang et al., 2015a). Therefore, the main question to be answered by our research is as follows: was this large-scale discontinuous weak zone caused by a huge ancient rock slide or by a local fault graben structure? If it was concluded that it is a huge landslide, how did that ancient slide happen? Is it stable and safe under the filling-drawdown cycles of the Three Gorges Reservoir?

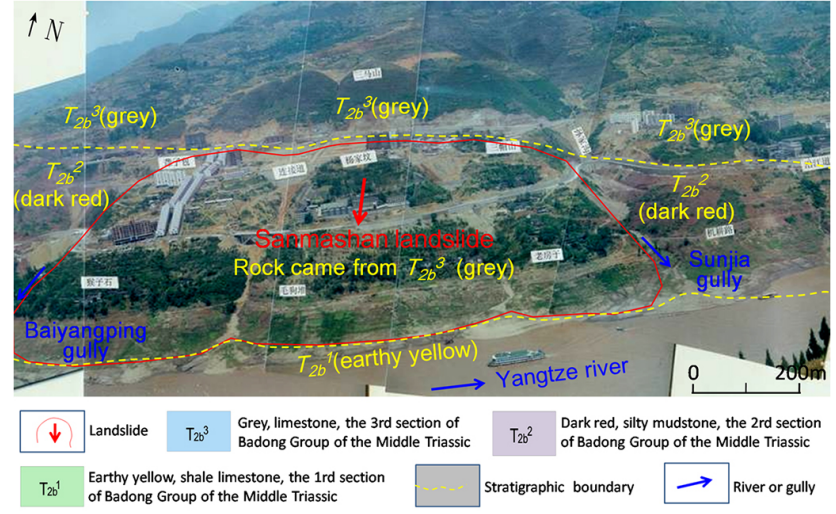

Figure 2. Panoramic photograph of the Sanmashan landslide before the Three Gorges Reservoir filled with water and before the relocation of the new Fengjie town (photograph was taken by Nanjiang Geological Team in 1998). The attitude of the bedrock bedding is $335-350^{\circ}<19-30^{\circ}$, but the rock in the Sanmashan landslide is dislocated. The elevation of Yangtze river water level is about $80 \mathrm{~m}$ a.s.l. View direction is NW.

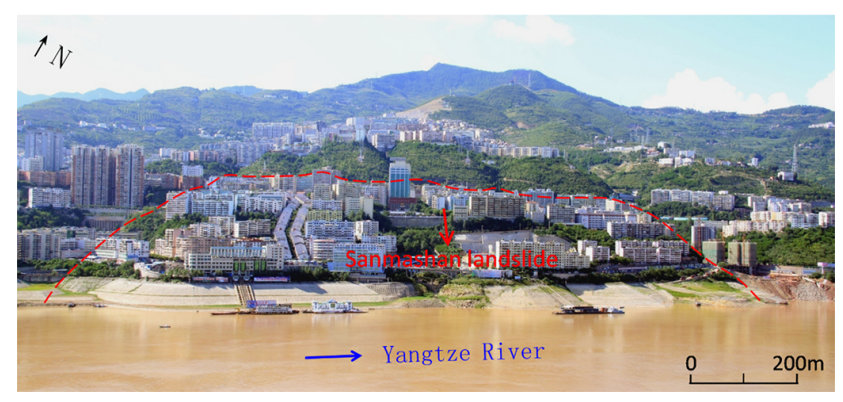

Figure 3. The residential buildings on the Sanmashan landslide in the new Fengjie town after the Three Gorges Reservoir filled with water (photograph taken 6 July 2013). The elevation of the Yangtze river water level is about $147 \mathrm{~m}$ a.s.1.

To solve these questions, the authors have carried out geological investigations and mapping, performed a deep exploration borehole, and carried out rock and soil mechanics tests, a large centrifuge model experiment, and a stability analysis.

\section{Geological background}

\subsection{Regional geological tectonics}

There are three major geomorphological levels in China ( $\mathrm{Li}$ et al., 2001). The new Fengjie town in the Three Gorges Reservoir area is close to the eastern margin of the second level. This region is part of the Yangtze platform, a tectonic unit in which the basement rocks are mainly composed of early Proterozoic metamorphic volcaniclastic rocks and intrusive magmatic rocks. The overlying sedimentary rocks, deposited during the Triassic, were folded and uplifted dur- 
ing the Yanshan phase at the end of the Jurassic. The upper Yangtze platform fold belt, the marginal depression of the Sichuan Basin, and the Dabashan platform fold belt converge in this region (No. 107 Geological Team of Sichuan Province, 1980) (Figs. 4 and 5).

\subsection{Strata, rocks, and soils}

The rocks in the new Fengjie town area are of Triassic age (No. 107 Geological Team of Sichuan Province, 1980; Li et al., 2006).

- The Early Triassic Jialingjiang group $\left(T_{1 j}\right)$ was deposited in a shallow lagoon facies, and contains sedimentary limestone, dolomitic limestone, and limestone.

- The Middle Triassic Badong group ( $\left.T_{2 \mathrm{~b}}\right)$ was formed in inland lakes and lagoon facies, with both clastics and carbonate deposition. The rocks consist of mudstone, silty mudstone, marly limestone, and limestone. This group $\left(T_{2 \mathrm{~b}}\right)$ is divided into four units, $T_{2 \mathrm{~b}}^{1}, T_{2 \mathrm{~b}}^{2}, T_{2 \mathrm{~b}}^{3}$ and $T_{2 \mathrm{~b}}^{4}$ (Fig. 6).

- The overburden soils contain landslide deposit $\left(Q^{\text {del }}\right)$, residual and deluvium deposit ( $\left.Q^{\text {edl }}\right)$, alluvial and diluvial deposit $\left(Q^{\mathrm{apl}}\right)$, and artificial fill $\left(Q^{\mathrm{ml}}\right)$.

\section{Analysis of the local geological structure}

\subsection{Geological field study and mapping}

After reviewing the available geological maps, aerial photographs, previous papers, and reports on the area (No. 107 Geological Team of Sichuan Province, 1980; Chen and Zhang, 1998; Nanjiang Geological Team, 1999), we conducted field work and geological mapping and collected the following information: the stratigraphic distribution in the Sanmashan area (shown in Fig. 7); the outcrop features of bedding and rock types in the Sanmashan area (shown in Fig. 6); and the cross section of the key geological structure and lithologies, the Zhuyi anticline in the new Fengjie town area (shown in Fig. 8). The palaeostress reconstruction of the tectonic stress field in the Sanmashan area, the attitude of the two limbs of the Zhuyi anticline (Fig. 9) and its conjugate shear joints (Fig. 10) are analysed in Fig. 11.

\subsection{Analysis and discussion of local geological structure}

It is well known that the formation, orientation, and evolution of faults and joints in rock are controlled by the palaeotectonic stress field. Conversely, the tectonic stress field can be deducted from the mechanical properties of faults and joints and their structural geological orientation. The Zhuyi anticline at the Sanmashan area is a double inverted anticline (an overturned and closed fold with a dipping axial plane and overturned strata) with strong crushing of strata in the core of

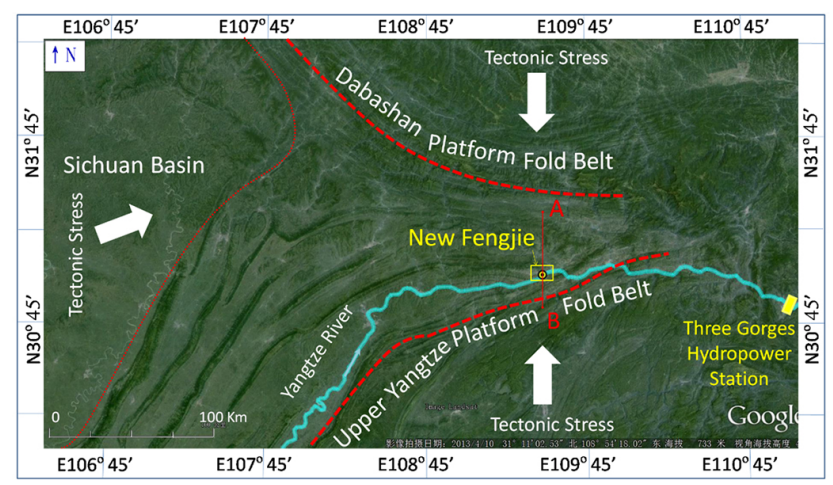

Figure 4. Regional tectonic domains and geostress fields (image from Google earth).

the Zhuyi anticline (Figs. 7-10). This shows that compressive stresses have resulted in closed folding and compressional thrust structures. With the help of the stereographic projection analysis of the conjugate shear jointing and the overturned bedding, the regional maximum compressive stress direction in the new Fengjie town can be determined as 344 $352.5^{\circ}$ (north-south) (Figs. 11 and 4). The character of faults (shear or tension) is determined by the tectonic stress field (Illies, 1981; Chang et al., 1981). Normal faults need attentional stress field, so a local fault graben (BIS-CWRC, 1997, 1999) (see Supplement 1) could not have formed under the regional compressive tectonic stress field conditions in this area.

We especially investigated the four normal faults in the field, $F_{8}, F_{20}, F_{19}$, and $F_{26}$, which form the local fault graben (BIS-CWRC, 1997, 1999) (see Supplement 1). They share some common characteristics which do not fit with a local fault graben for the following reasons. (1) The extension lengths of the faults are not long enough $\left(F_{8}: 1110 \mathrm{~m}\right.$, $F_{19}: 150 \mathrm{~m}, F_{26}: 100 \mathrm{~m}$ ), the fault fracture zone is not wide ( $F_{8}: 3.5 \mathrm{~m}, F_{19}: 0.1-1.1 \mathrm{~m}, F_{26}: 1-2 \mathrm{~m}$ ), but the fault displacement is very large $\left(F_{8}: 150-180 \mathrm{~m}, F_{26}: 25-35 \mathrm{~m}\right)$. According to geological mechanics (Illies, 1981; Chang et al., 1981 ), four normal faults of this type, $F_{8}, F_{20}, F_{19}$, and $F_{26}$ (BIS-CWRC, 1997, 1999), cannot form in a compressive tectonic stress field. (2) The footwall rock mass of the faults is preserved intact, but the hanging wall is almost entirely disintegrated, which does also not support the formation of normal faults around a local fault graben. (3) The thickness of $T_{2 \mathrm{~b}}^{2}$ in the local fault graben is only $200 \mathrm{~m}$ (BIS-CWRC, 1997, 1999). According to earlier research (No. 107 Geological Team of Sichuan Province, 1980; Li et al., 2006), the thickness of $T_{2 \mathrm{~b}}^{2}$ is regionally about $500 \mathrm{~m}$, which means that about $300 \mathrm{~m}$ thickness of $T_{2 \mathrm{~b}}^{2}$ has been lost in the fault graben (BIS-CWRC, 1997, 1999). (4) Faults $F_{20}$ and $F_{26}$ have not been found on the spot. Faults $F_{8}$ (which is actually a rear sliding rupture of the ancient slide, shown in Fig. 14c) and $F_{19}$ (a sliding zone of the ancient slide, shown in Fig. 14f) 


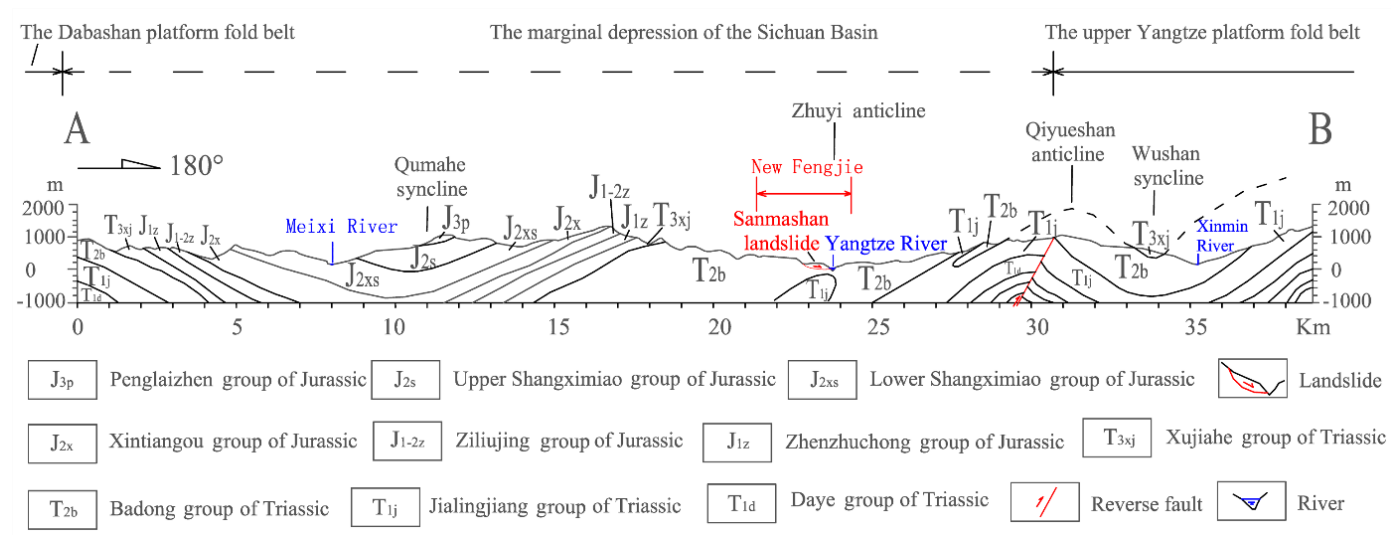

Figure 5. Schematic N-S geological cross section of background with regional tectonic domains. The location of the A-B profile is shown in Fig. 4.

(D01)

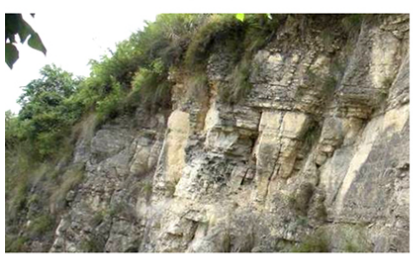

(D03)

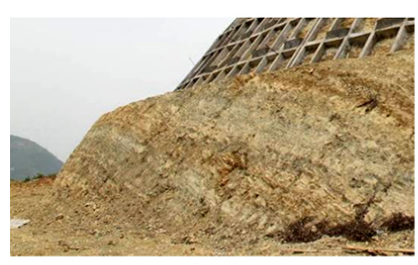

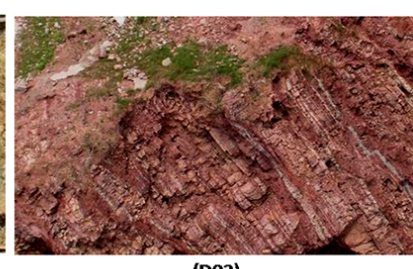

(D02)

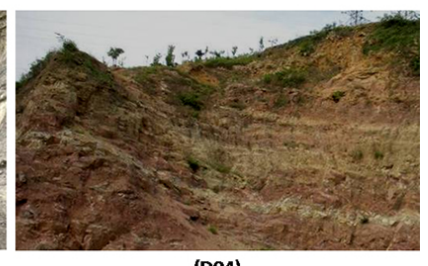

(D04)
Figure 6. Rock outcrops in the new Fengjie town area. D01: the first section of the Middle Triassic Badong group ( $T_{2 \mathrm{~b}}^{1}$ beds). D02: the second section of the Middle Triassic Badong group ( $T_{2 \mathrm{~b}}^{2}$ beds). D03: the third section of the Middle Triassic Badong group $\left(T_{2 \mathrm{~b}}^{3}\right.$ beds). D04: the fourth section of the Middle Triassic Badong group ( $\mathrm{T}_{2 \mathrm{~b}}^{4}$ beds). The outcrop locations of D01, D02, D03 and D04 are shown in Fig. 7.

show the characteristics of pressure-shear sliding rather than tension as would be expected at a normal fault. Thus an analysis of the results of our field data collection does not agree with the hypothesis of a local fault graben as the cause of the large discontinuous weak layer in the Sanmashan area.

These data provide rather a large amount of evidence for the assumption that this area is a huge deep-seated ancient rock slide.

\section{Identification of the Sanmashan landslide}

\subsection{Methodology}

Detailed geological mapping, the investigation of an exploratory tunnel and a foundation pit, and the logging of 21 deep bore holes were carried out at the site. The results are shown in a detailed geological map of the new Fengjie town area at a scale of $1: 10000$ (Fig. 7), and an engineering geological map of the Sanmashan landslide at a scale of $1: 1000$ (Fig. 12). The outline of the landslide, the geomorphological features and the sliding traces and structural geological features of the Sanmashan landslide are shown in Figs. 12-14. Eighteen samples were collected from the sliding plane, the slide mass and bedrock for the geotechnical laboratory tests.

\subsection{Geomorphological features and sliding traces}

A steep $\left(70^{\circ}\right)$ cliff, over $130 \mathrm{~m}$ in height, forms the back scarp of the landslide (Figs. 13 and 14b), a gully called Baiyangping forms the western lateral boundary, and a gully called Sunjia forms the eastern lateral boundary, while the Yangtze River (the Three Gorges Reservoir) forms the front of the landslide. The terrain slope angle of the landslide is $15-$ $20^{\circ}$. The length of the landslide is over $780 \mathrm{~m}$, the width is about $1020 \mathrm{~m}$, and the maximum thickness is over $150 \mathrm{~m}$. The average thickness is about $125 \mathrm{~m}$, and the volume is about 100 million $\mathrm{m}^{3}$ (Figs. 12 and 13). The geomorphological characteristics of the Sanmashan landslide are as follows.

During the construction of the new Fengjie town in 2000, the sliding plane in the upper part of the landslide and the scarp were exposed in a foundation excavation (Fig. 14c). The sliding surface is very obvious and very smooth, showing the characteristics of squeezing and sliding.

The sliding plane at the eastern lateral boundary has a thickness of $1.1 \mathrm{~m}$ (Fig. 14e). It is exposed in the exploratory tunnel near the eastern lateral boundary, it is very smooth, and also shows the characteristics of squeezing and sliding 


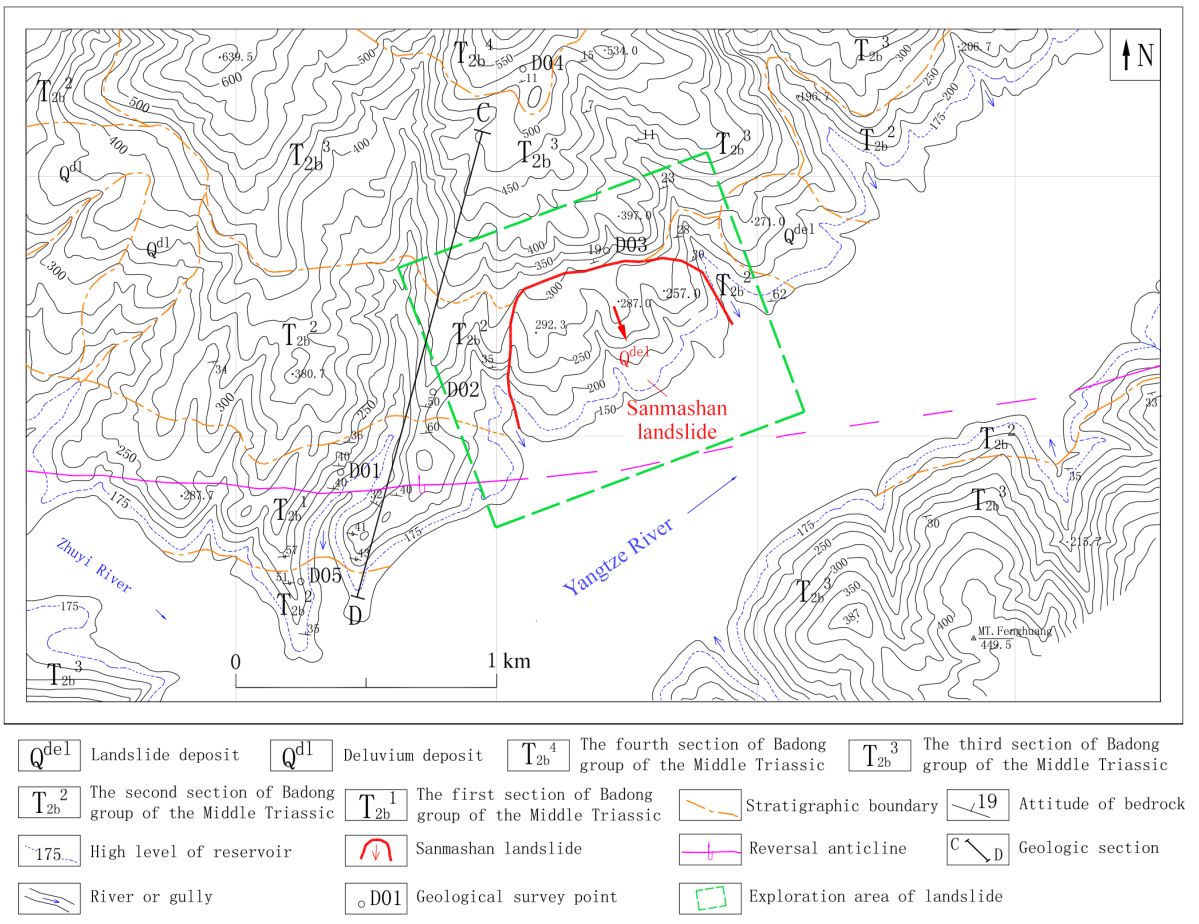

Figure 7. Geological map at 1:10000 scale of the new Fengjie town area. The location is the area of the yellow box in Figs. 1 and 4 . The topographic map was prepared in 1990 before the relocation of the new Fengjie town. The area of the green box in this map is an area of major site investigations (see Fig. 12).

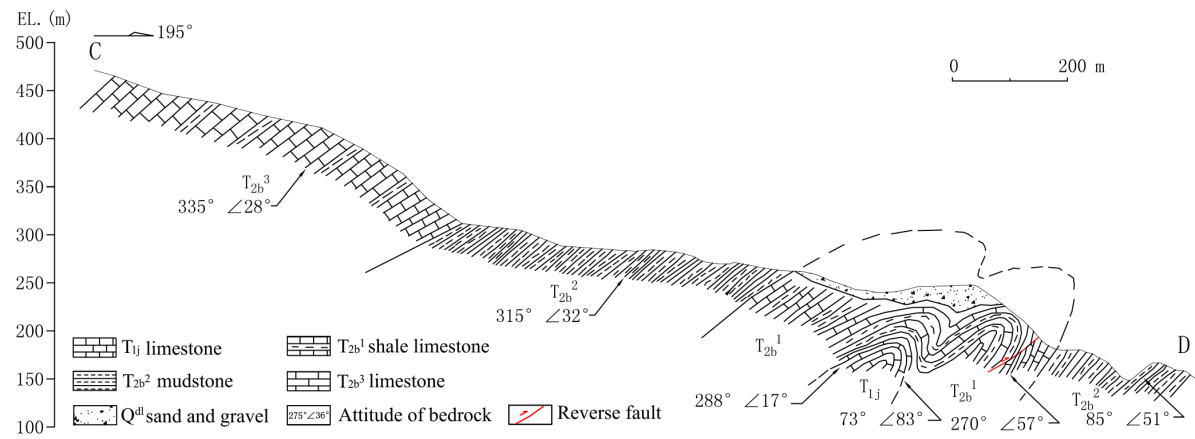

Figure 8. Geological cross section of the Zhuyi anticline. The location of the C-D cross section is shown in Fig. 7. It is a double overturned anticline, see also Figs. 9 and 10.

(Fig. 14f). These sliding traces are very clear, but have been misidentified as faults $F_{19}$ in earlier research (BIS-CWRC, 1997, 1999) (see Supplement 1).

The western lateral boundary, called Longzibaogou, leads into the Yangjiaping gully (Figs. 12 and 14). The sliding surface there was found and observed in a horizontal borehole (Fig. 14g); the slickensides are clear and smooth.

The elevation above sea level of the toe of the landslides about $90 \mathrm{~m}$. There are three secondary (partial) landslides at the foot of the Sanmashan landslide called the Houzishi, Zhiwuyou, and Laofangzi landslides (Figs. 12-14).

\subsection{Geological structure of the landslide}

The Sanmashan landslide can be subdivided into four domains (I-IV) based on differences in morphology, geological structure, and inferred failure mechanics (Figs. 12 and 14). Seven engineering geological units were identified in these four domains (Fig. 13).

- Units 1 and 2 are the landslide deposits $\left(Q^{\text {del }}\right)$ (Fig. 13) with a thickness of up to $150 \mathrm{~m}$. (1) The first unit is dense to very dense, and contains grey or dark grey crushed stone in a matrix of silty clay and sand. The crushed stone is derived from limestone $\left(T_{2 \mathrm{~b}}^{3}\right)$. A large 
Table 1. Physical, mechanical, and hydraulic properties for the five main geologic units.

\begin{tabular}{lrrlrll}
\hline Geologic unit & $\begin{array}{r}\text { Modulus/ } E \\
(\mathrm{MPa})\end{array}$ & $\begin{array}{c}\text { Poisson's } \\
\text { ratio/ } \\
v\end{array}$ & $\begin{array}{l}\text { Unit } \\
\text { weight/ } \\
r\end{array}$ & $\begin{array}{r}\text { Cohesion/ } \\
c(\mathrm{kPa})\end{array}$ & $\begin{array}{l}\text { Internal } \\
\text { friction } \\
\text { angle/ } \\
\phi\left({ }^{\circ}\right)\end{array}$ & $\begin{array}{l}\text { Saturated } \\
\text { permeability/ } \\
K_{\mathrm{S}}\left(\mathrm{m} \mathrm{s}^{-1}\right)\end{array}$ \\
\hline$Q^{\text {del }}\left(T_{2 \mathrm{~b}}^{3}\right)$ & 85 & 0.35 & 22.5 & 28 & 33 & $1 \times 10^{-5}$ \\
$Q^{\text {del }}\left(T_{2 \mathrm{~b}}^{2}\right)$ & 50 & 0.40 & 21 & 30 & 18.2 & $5 \times 10^{-8}$ \\
Limestone $\left(T_{2 \mathrm{~b}}^{3}\right)$ & 4800 & 0.25 & 26 & 200 & 40 & $10^{-9}$ \\
Mudstone $\left(T_{2 \mathrm{~b}}^{2}\right)$ & 1500 & 0.35 & 23 & 100 & 25 & $10^{-9}$ \\
Shale limestone $\left(T_{2 \mathrm{~b}}^{1}\right)$ & 3000 & 0.30 & 24.8 & 120 & 35 & $10^{-9}$ \\
\hline
\end{tabular}

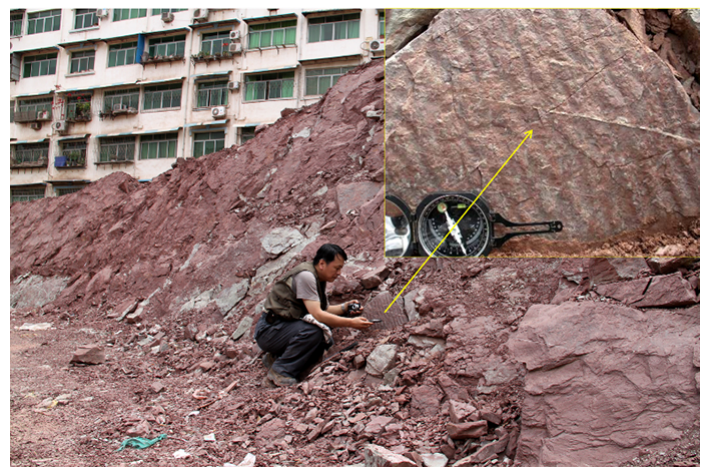

Figure 9. The bedding plane on the south limb of the Zhuyi anticline. The ripple marks show that the sequence is overturned.

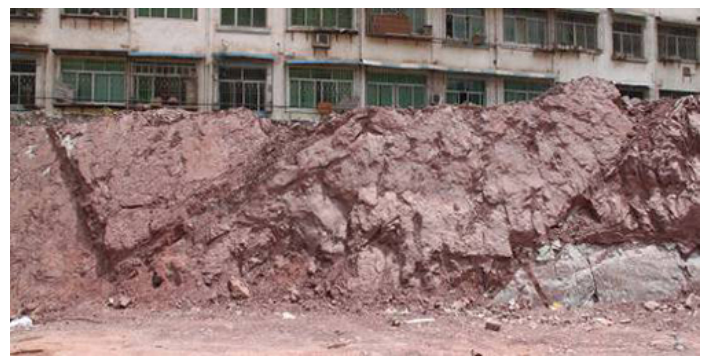

Figure 10. Conjugate shear joints of in rock outcrop on the south limb of the Zhuyi anticline.

foundation pit was constructed in this unit in the centre of the landslide (Fig. 14i). The slide zone of the Zhiwuyou secondary landslide is exposed in the eastern wall of this pit (Fig. 14j) and the rock masses in the western wall have anomalous attitudes with respect to each other (Fig. 15). (2) The second unit is even more dense, reddish or dark red/brown and contains crushed stone in a matrix of clay and silty clay. The crushed stone is derived from mudstone and silty mudstone $\left(T_{2 \mathrm{~b}}^{2}\right)$.

- Units 3, 4, and 5 are the bedrock ( $T_{2 \mathrm{~b}}$ ) (Fig. 13). (3) The third member of the Badong group $\left(T_{2 \mathrm{~b}}^{3}\right)$ contains grey

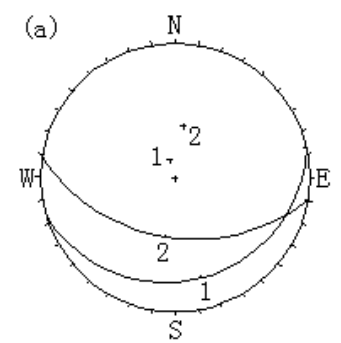

Orientations

ID Dipping direction/dip angle

$1165 / 75$

$2189 / 48$

Equal angle

Upper hemisphere

52 Poles

52 Entries

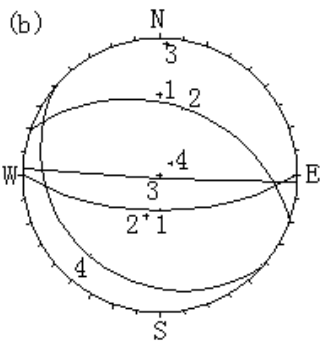

Orientations

ID Dipping direction/dip angle

$1180 / 29$

$2019 / 55$

$3183 / 2$

$221 / 76$

Equal angle

Upper hemisphere

28 Poles

28 Entries

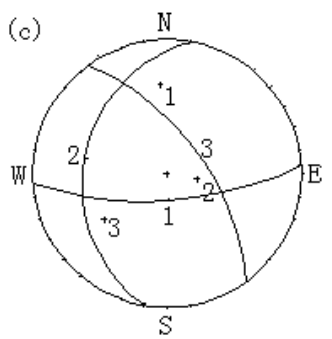

Orientations

ID Dipping direction/dip angle

$1176 / 23$

$2280 / 64$

$3054 / 30$

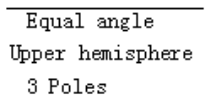

3 Poles

3 Entries

Figure 11. Stereographic projection of the orientation of the two limbs of the Zhuyi anticline and the conjugate shear joints. (a) The attitude of the north limb of the Zhuyi anticline, measuring point (D01) and (D02) (location see Figs. 6 and 7). (b) The attitude of the south limb of the Zhuyi anticline, measuring point at location of Fig. 9. (c) Conjugate shear joints, measuring point at location of Fig. 10.

or dark grey limestone, with a local thickness of up to $205 \mathrm{~m}$. (4) The second member of the Badong group $\left(T_{2 \mathrm{~b}}^{2}\right)$, which consists of kermesinus or dark red/brown mudstone and silty mudstone, has a local thickness of up to $550 \mathrm{~m}$. (5) The first section of the Badong group of 

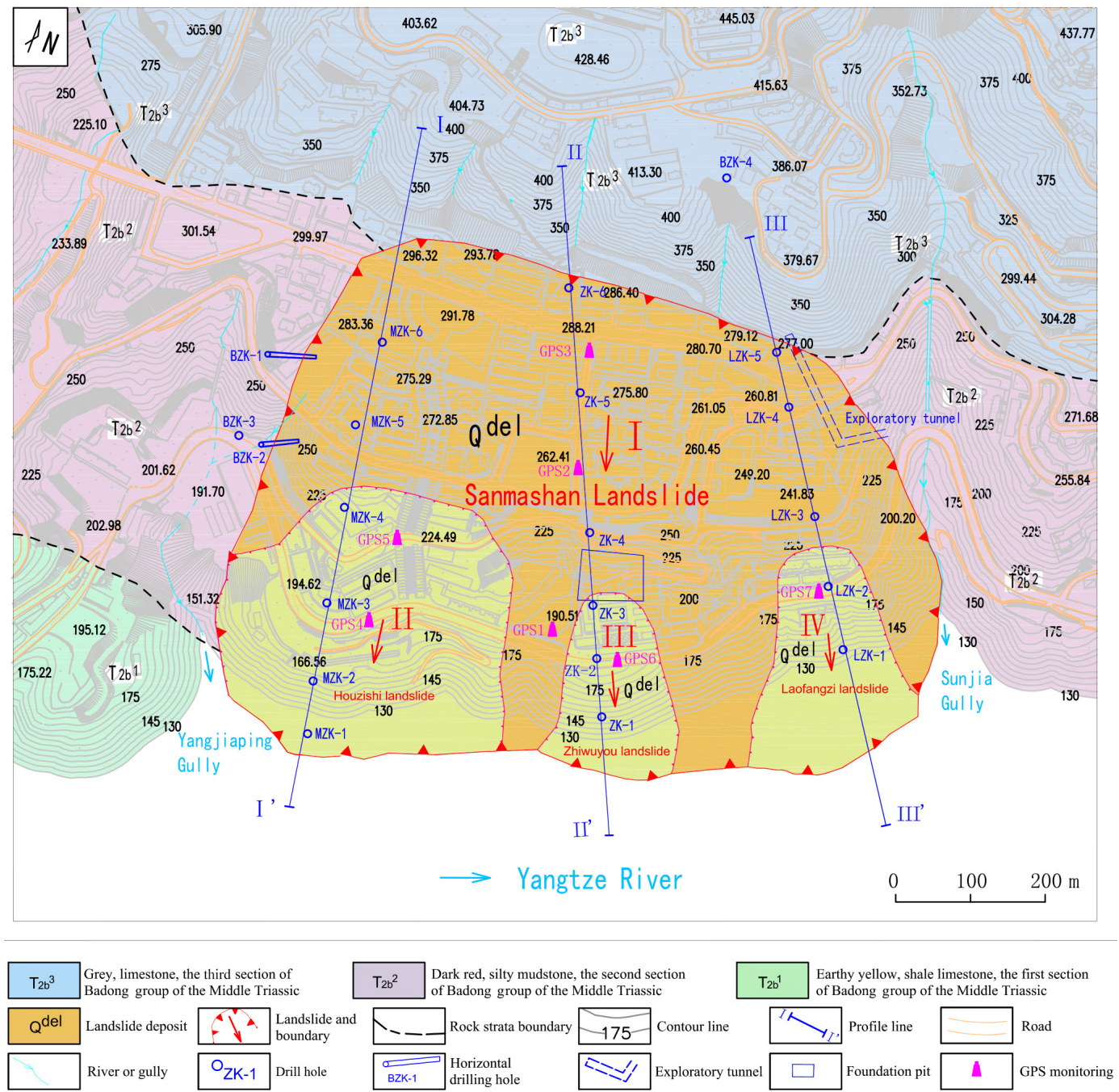

Figure 12. Geological map at a scale of $1: 1000$ of the Sanmashan landslide (the topographic base map is surveyed in 2004). The location of map is the area of the green box in Fig. 7. The area of the Sanmashan landslide is subdivided into four domains (I-IV). The three secondary partial landslides are outlined at the foot of the Sanmashan landslide.

the Middle Triassic $\left(T_{2 \mathrm{~b}}^{1}\right)$ consists of yellowish or light grey shale limestone, with a local thickness of about $70 \mathrm{~m}$.

- Unit 6 is alluvium and proluvium $\left(Q^{\text {apl }}\right)$ (Fig. 13). (6) It is loose to slightly dense and contains subrounded to rounded gravel, cobbles, and mixed boulders of limestone and silty mudstone in a matrix of sand, deposited at the front of the landslide. The observed unit thickness is up to $15 \mathrm{~m}$.

- Unit 7 is artificial fill soil $\left(Q^{\mathrm{ml}}\right)$ (Fig. 13). (7) It is loose to dense, consists of concrete, clay, and sand within mixed with crushed stone, and is randomly filled with depressions or spread out on top of the landslide surface. The observed unit thickness is up to $10 \mathrm{~m}$.

\subsection{Properties of the materials in the landslide}

Eighteen samples were collected from the sliding zone, the slide mass, and the bedrock below the Sanmashan landslide. The physical and mechanical parameters of the main six geologic units were determined by laboratory testing. Cohesion and internal friction angle were obtained from triaxial saturated consolidated undrained shear tests. The saturated permeability coefficient of the slide mass was acquired by double-ring infiltration testing in the field. The saturated permeability coefficients of the bedrock are estimated values. The test results are shown in Table 1 and were used for the following analysis. 

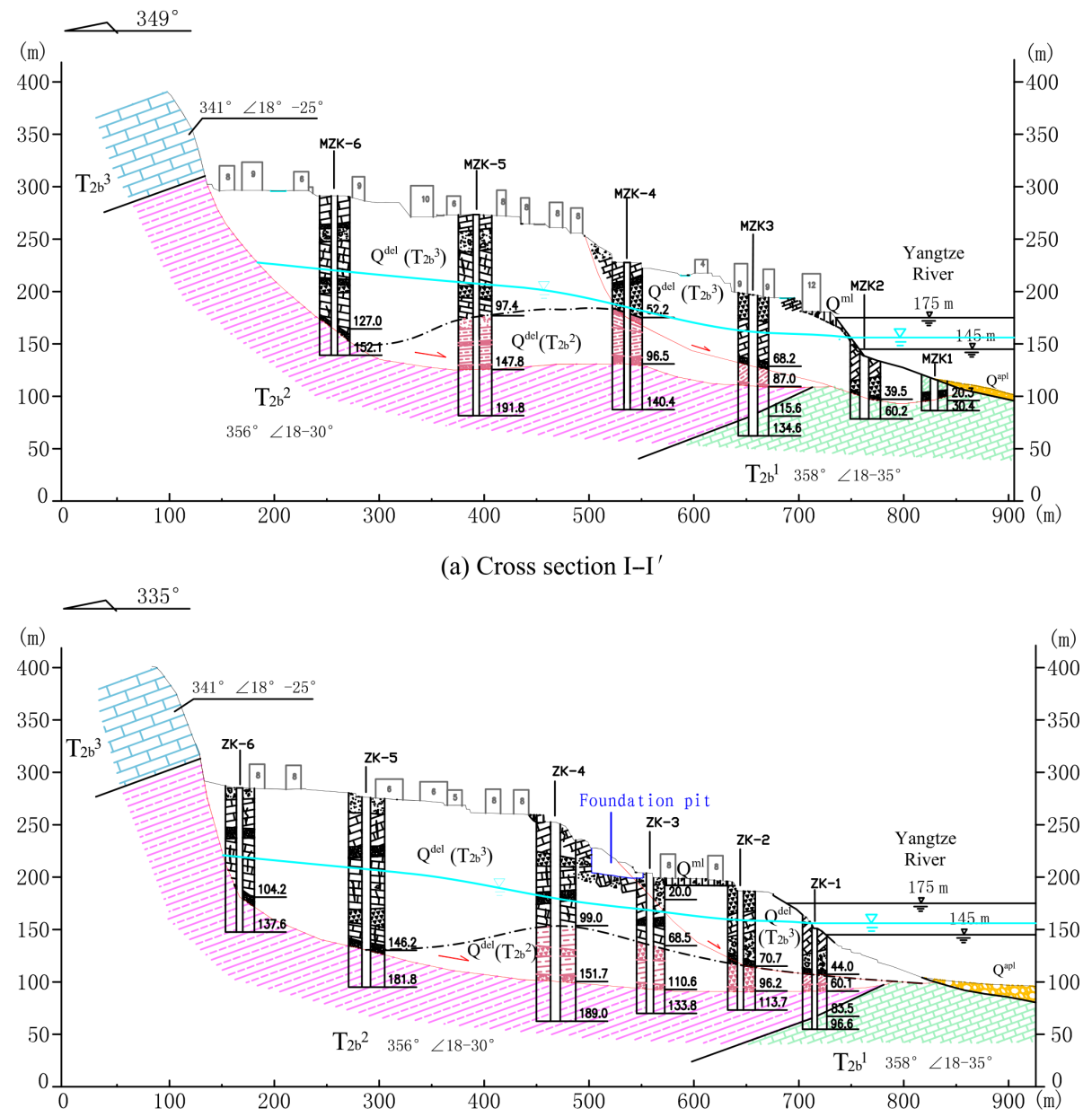

(b) Cross section II-II'

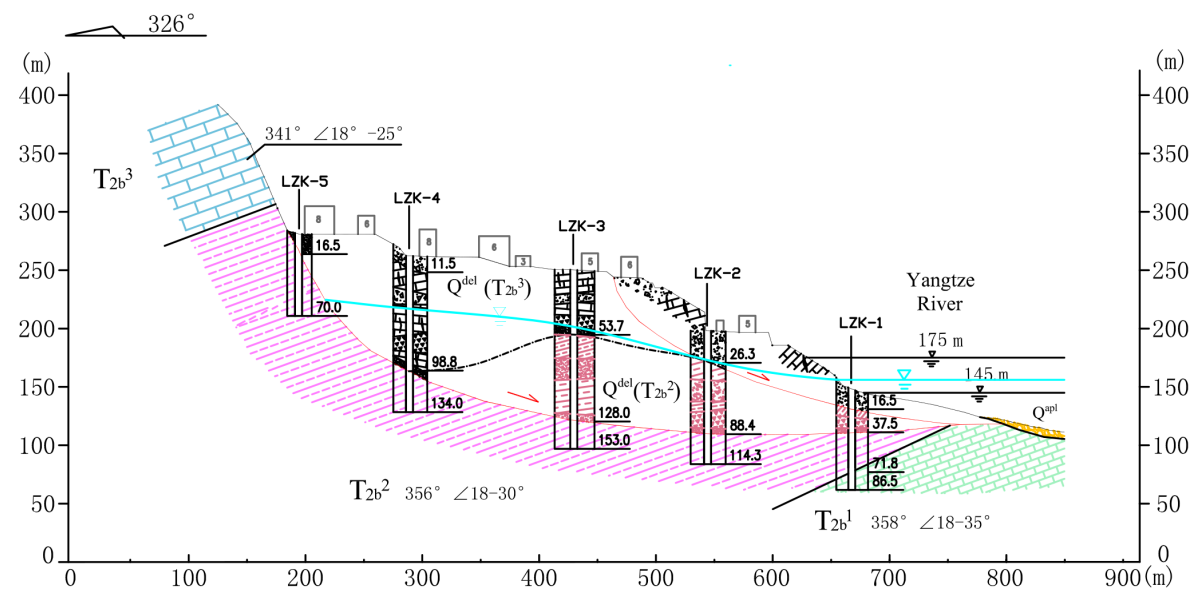

(c) Cross section III-III'

\begin{tabular}{|c|c|c|}
\hline $\mathrm{T}_{2 b^{3}}$ Limestone & $\mathrm{T}_{2 b^{2}}$ Mudstone $\mathrm{T}_{2} \mathrm{~b}^{1}$ Shale limestone & $\square$ Explored sliding face \\
\hline$\therefore \mathrm{Q}^{\mathrm{del}}$ Soil and detritus & 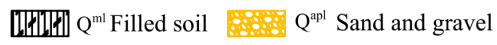 & Udepth Drilling hole and depth(m) \\
\hline
\end{tabular}

Figure 13. Geological cross sections through the Sanmashan landslide. The location of the cross sections is shown in Fig. 12. (a) Cross section I-I'. (b) Cross section II-II'. (c) Cross section III-III'. 


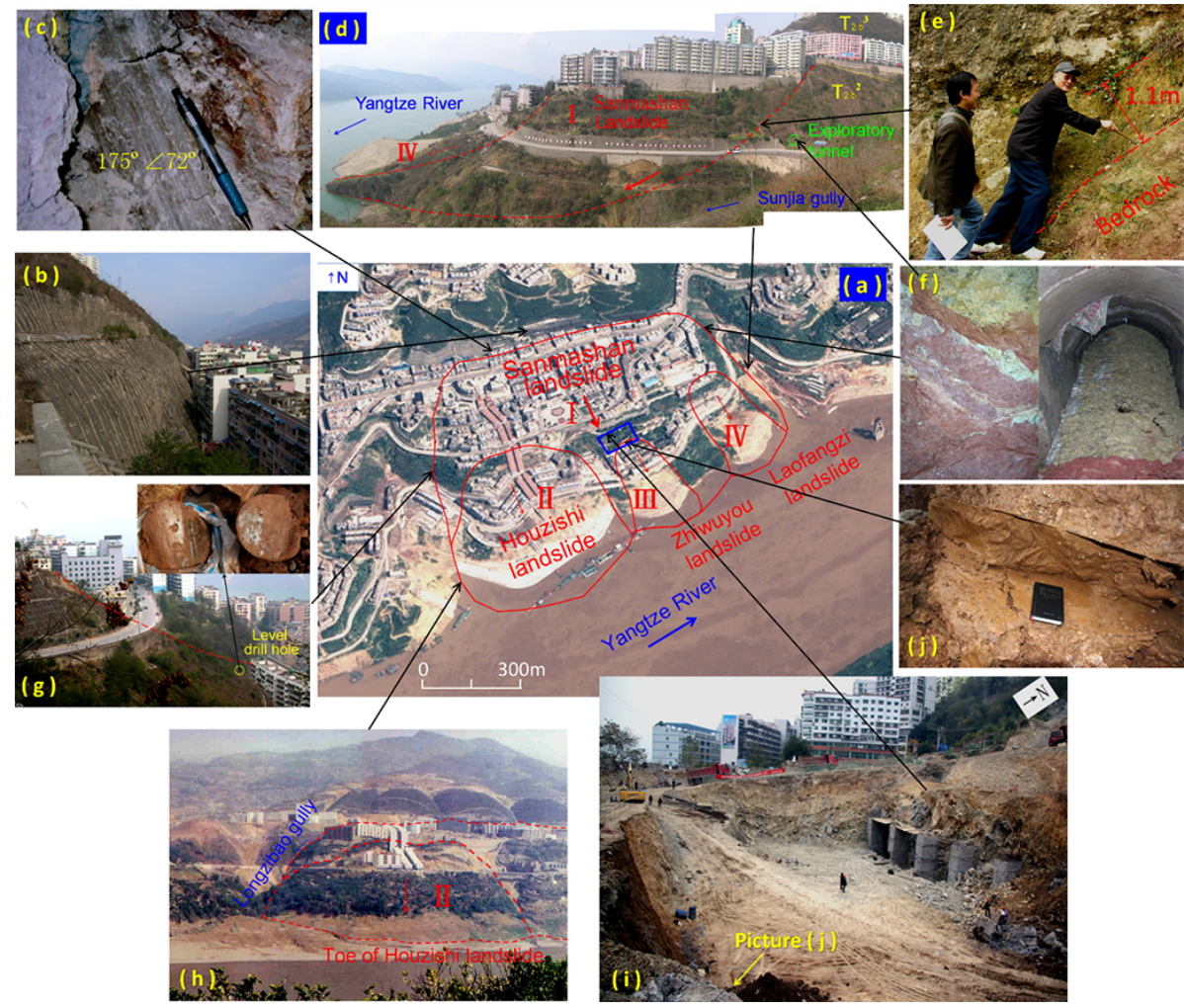

Figure 14. Various views of the Sanmashan landslide. (a) Quickbird image map (September 2004). Area is subdivided into four domains (I-IV). (b) The crown and scarp of the Sanmashan landslide. (c) Slickenside discovered in a foundation excavation in 2000 (taken by Zhengquan Cui). (d) Landslide seen from the east. (e) Sliding zone near the eastern boundary. (f) The sliding zone in the exploratory tunnel. (g) The sliding scarp in a horizontal drilling hole near the western boundary. (h) The western slide boundary and the toe of the Houzishi secondary landslide in 2000. (i) Large foundation pit (in 2013), in which the sliding zone of the Zhiwuyou secondary landslide is exposed (see also (j) and Fig. 15).

\subsection{Deformation characteristics}

According to residents, a small shallow soil slide and the formation of cracks had already occurred at the front of the secondary (partial) landslide during rainfall before 2003.

The filling-drawdown cycles of the Three Gorges Reservoir from June 2003 to December 2015 are shown in Fig. 16. (i) On 1 June 2003, the first reservoir filling phase started. On 10 June 2003, the reservoir level reached an elevation of 135 m. (ii) On 20 September 2006, the Three Gorges Reservoir second phase of the reservoir filling started. On 27 October 2006, the reservoir level reached an elevation of $156 \mathrm{~m}$. (iii) On 28 September 2008, the third phase of the reservoir filling started. On 14 November 2008, the reservoir level reached an elevation of $171.81 \mathrm{~m}$. On 26 October 2010, the reservoir level reached its maximum design elevation level of $175 \mathrm{~m}$.

During the first phase of the reservoir filling, several cracks were found in the surface of the Houzishi landslide in December 2004. The first crack occurred at an elevation of $150 \mathrm{~m}$, had a length of $17 \mathrm{~m}$ and a width varying from 5 to $28 \mathrm{~mm}$. GPS monitoring of the deformations was carried out by the local government at locations shown in Fig. 12 . GPS1, GPS2, and GPS3 were located near the central axis of the Sanmashan landslide, GPS4 and GPS5 on the Houzishi landslide, GPS6 on the Zhiuwuyou landslide, and GPS7 on the Laofangzi landslide. The monitoring data were collected twice a month starting on 5 July 2006, but this frequency was increased in the rainy season. The results of the GPS monitoring are shown in Fig. 17.

The displacement curves show that the total displacements of GPS1, GPS2, and GPS3 remain near zero, which show that the middle and back parts of the Sanmashan landslide are stable. However, the total displacements of GPS4 and GPS5 were 19.3 and $16.4 \mathrm{~mm}$ from 5 July 2006 to 31 December 2011 on the Houzishi landslide. The total displacements of GPS6 and GPS7 were only 6.7 and $9.8 \mathrm{~mm}$ for the Zhiwuyou and Laofangzi landslides respectively. Analysis of the relation with reservoir level and rainfall, the displacements began to increase after the filling phases of 20 September 2006 and 28 September 2008. Since May 2009, however, none of the GPS monitored displacements have increased further. We assume that the Sanmashan landslide as a whole is inactive nowadays, but a partial reactivation of the land- 

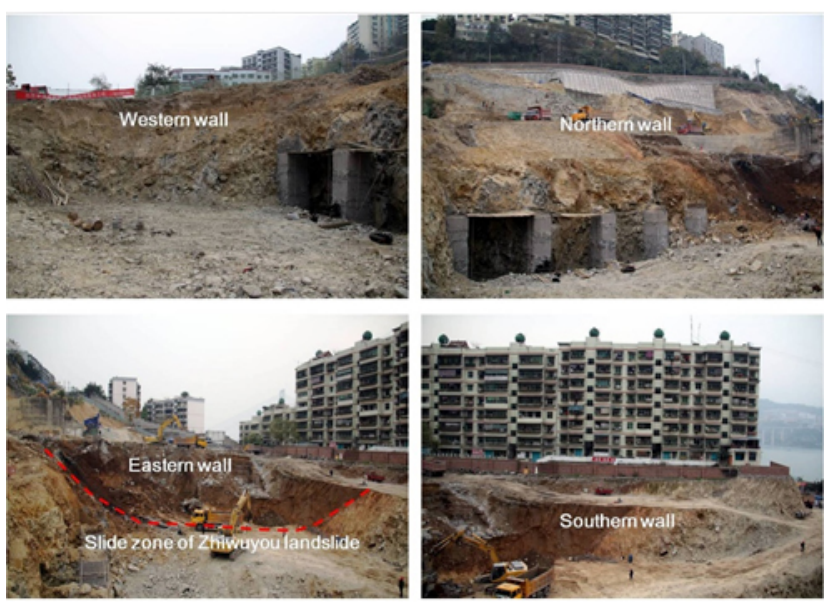

(a)

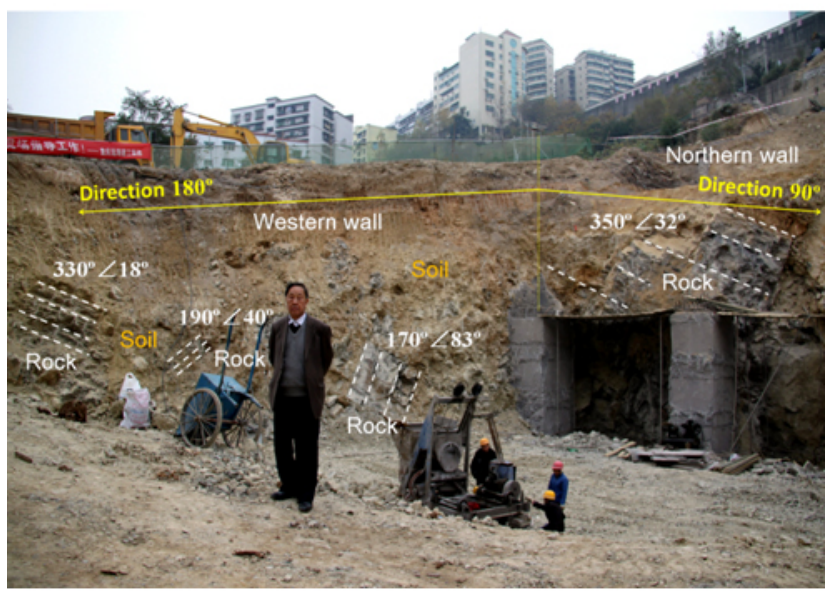

(b)

Figure 15. (a) The structural geological features of the landslide body in four walls of the foundation excavation. (b) The rock mass inside the Sanmashan landslide body in the western wall of the foundation excavation shows chaotic attitudes as generally generated by landslides.

slide can be induced by reservoir water fluctuations or rainfall.

\section{Formation mechanism and process of the ancient slide}

Figure 13 shows that the original surface of the ancient slide was a gently inclined slope consisting of limestone of $T_{2 \mathrm{~b}}^{3}$ in its upper part and mudstone and siltstone of $T_{2 \mathrm{~b}}^{2}$ in its lower part. It is a hard-on-soft rock slope that provides a basis for the sliding; a free face is provided by the downcutting of the Yangtze River. These factors finally led to the formation of the ancient Sanmashan slide. Analysis of our field observations shows that there is a high steep cliff in the crown of the landslide and that the surface of rupture and sliding is

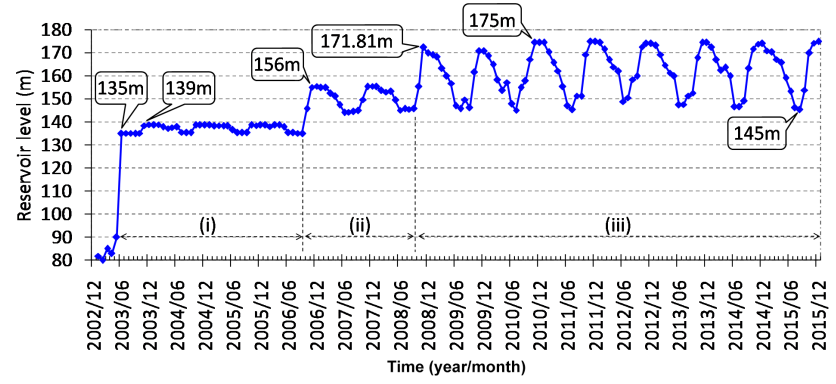

Figure 16. Filling-drawdown cycles of the reservoir from 2003 to 2015 .

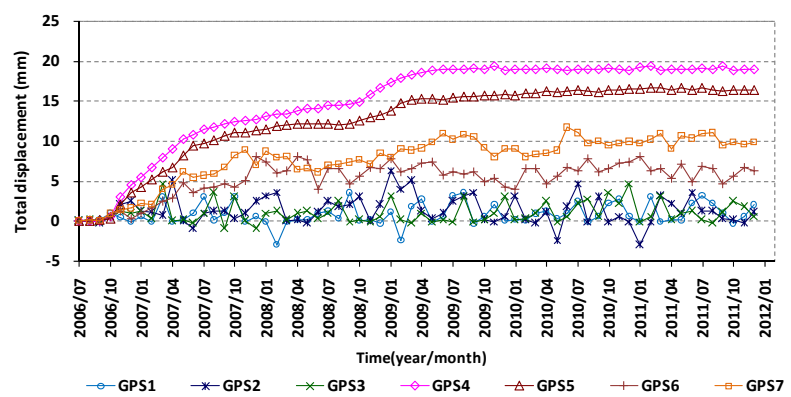

(a)

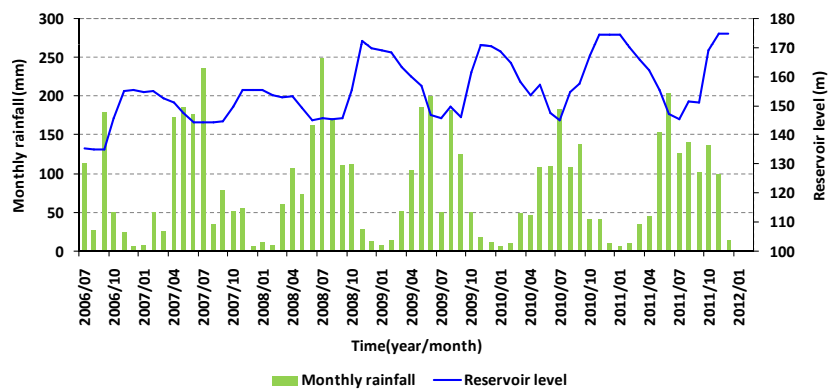

(b)

Figure 17. (a) The result of GPS monitoring and (b) reservoir level and rainfall from 5 July 2006 to 31 December 2011. The location of GPS monitoring points are shown in Fig. 12.

concavely curved. So the ancient slide of Sanmashan is most likely a rotational rock slide (Varnes, 1978; WP/WLI, 1993; Cruden and Varnes, 1996; Huang, 2012; Hungr et al., 2014). In order to confirm this assumption, we have carried out a large centrifuge model experiment, which was briefly discussed and published earlier by Tang et al. (2015b). According to international standards (WP/WLI, 1993), we further analyse and discuss the formation process and failure mechanism of the Sanmashan ancient slide, which is essential in order to recognize a potential hazard.

\subsection{Geotechnical centrifuge test}

The centrifuge technology is widely applied in geotechnical and geological engineering, especially in the simulation of slope deformation and failure (Taylor, 1995; Nakajima and 
Table 2. The similarity coefficients for the main physical quantities in the centrifuge model.

\begin{tabular}{lll}
\hline $\begin{array}{l}\text { Physical quantity/ } \\
\text { symbol }\end{array}$ & Unit & $\begin{array}{l}\text { Similarity } \\
\text { coefficient }\end{array}$ \\
\hline Acceleration $/ a$ & $\mathrm{~g}$ & $N_{\mathrm{a}}=30$ \\
Dimension $/ L$ & $\mathrm{~m}$ & $N_{1}=1 / 3000$ \\
Density/ $\rho$ & $\mathrm{g} \mathrm{cm}^{-3}$ & $N_{\rho}=1$ \\
Modulus $/ E$ & $\mathrm{MPa}$ & $N_{\mathrm{E}}=N_{\rho} N_{\mathrm{a}} N_{\mathrm{l}}=1 / 100$ \\
Internal friction angle/ $\varphi$ & $\circ$ & $N_{\varphi}=1$ \\
Cohesion $/ c$ & $\mathrm{kPa}$ & $N_{\mathrm{c}}=N_{\rho} N_{\mathrm{a}} N_{1}=1 / 100$ \\
Poisson's ratio/ $\nu$ & - & $N_{v}=1$ \\
\hline
\end{tabular}

Table 3. Physical and mechanical parameters of the materials in the centrifuge model test.

\begin{tabular}{|c|c|c|c|c|c|}
\hline $\begin{array}{l}\text { Model } \\
\text { materials }\end{array}$ & $\begin{array}{c}\text { Modulus } \\
\text { (MPa) }\end{array}$ & $\begin{array}{l}\text { Poisson's } \\
\text { ratio }\end{array}$ & $\begin{array}{c}\text { Density } \\
\left(\mathrm{g} \mathrm{cm}^{-3}\right)\end{array}$ & $\begin{array}{c}\text { Cohesion } \\
(\mathrm{kPa})\end{array}$ & $\begin{array}{l}\text { Internal } \\
\text { friction } \\
\text { angle }\left(^{\circ}\right)\end{array}$ \\
\hline Model unit $1^{\mathrm{a}}$ & 30 & 0.30 & 2.48 & 1.2 & 35 \\
\hline Model unit $2^{b}$ & 15 & 0.35 & 2.30 & 1.0 & 25 \\
\hline Model unit $3^{c}$ & 48 & 0.25 & 2.60 & 2.0 & 40 \\
\hline
\end{tabular}

Stadler, 2006). A centrifuge is a piece of equipment that rotates an object around a fixed axis (it spins in a circle), applying a potentially strong centrifugal (outward) force perpendicular to the axis of spin. Geotechnical centrifuge modelling is used for physically testing soils and rock models. The centrifugal acceleration is applied to models to scale the gravitational acceleration and enable prototype scale stress in scale models. Problems can be studied such as occur in the design of foundations for buildings and bridges, the design of earth dams, tunnels, and analysis of slope stability, including effects such as blast loading and earthquake shaking. Large centrifuges are used to simulate high gravity or acceleration environments. For our model tests we used the centrifuge at the State Key Laboratory of Geohazard Prevention and Geoenvironment Protection in Chengdu, China (Fig. 18). With a maximum acceleration of $500 \mathrm{gt}$ it is the largest geotechnical centrifuge in Asia.

\subsection{Tested model}

The geological model of the original slope (Fig. 19) was generalized into a geotechnical test model (Fig. 20). Based on the previous research (Yang, 1988; Li et al., 2001), three periods of incision of the Yangtze River are assumed. According to the similarity theory (Taylor, 1995) and the dimension relationship between geological model and experimental model we determined the similarity coefficient (Table 2). From the physical and mechanical parameters of the geological units of the Sanmashan landslide (Table 1), we determined the

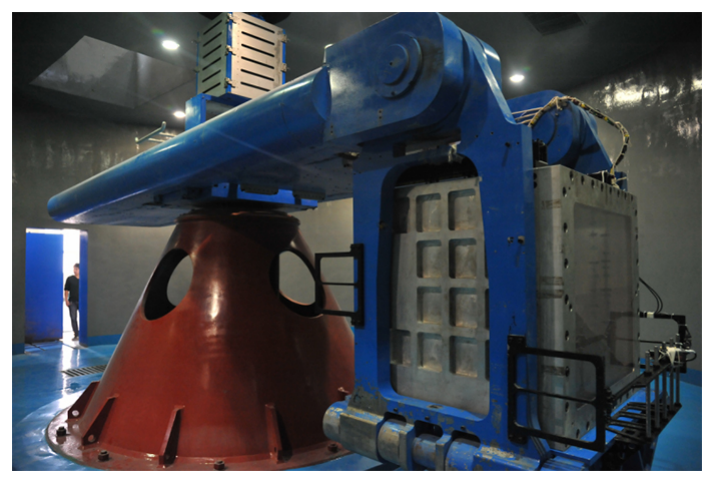

Figure 18. The geotechnical centrifuge used for the model test.

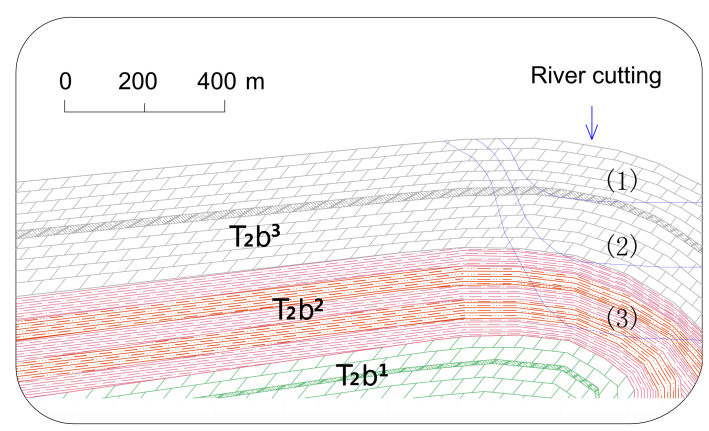

Figure 19. The assumed geological structure of the original river bank slope.

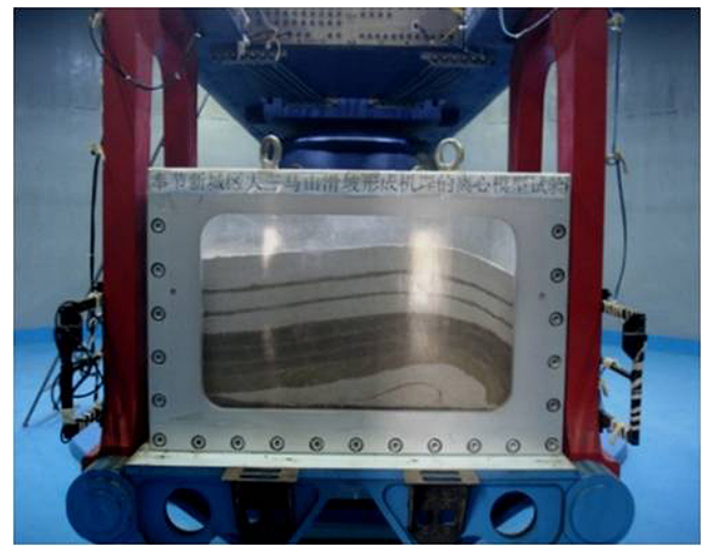

Figure 20. The centrifuge test model.

physical and mechanical parameters of the model materials with the similarity coefficient (Table 3 ).

\subsection{Analysis and discussion of results of centrifuge test}

The model test results were shown in an earlier study (Figs. 97.8-97.10, Tang et al., 2015b) (see Supplement 2). The deformation and failure process during the centrifuge test has the following characteristics. First, the soft rock in the lower part of the model slide body is deformed in shear. 


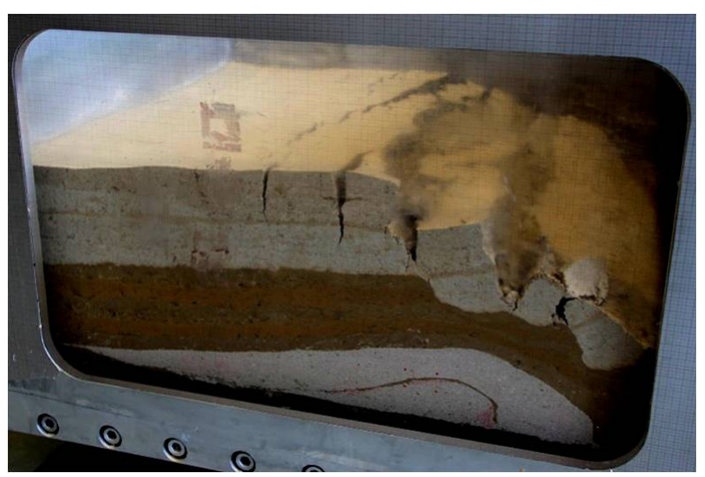

Figure 21. The model after slide. The rupture surface of the slide is roughly curved, successive rotational slides occurred around one axis.

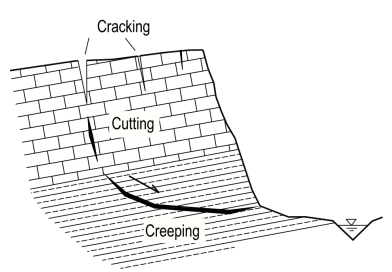

(a)

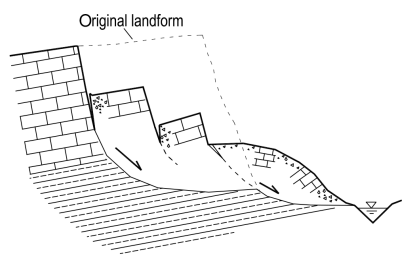

(b)
Figure 22. Schematic cross section of the Sanmashan ancient slide. (a) Slope deformation, (b) slope after slide.

Then, tension cracking occurs in the hard rock in the upper part. Finally, the rupture plane is formed when the tension cracks extend downwards towards the zone of shear deformation and the slide body moves. The deformation and failure process can be characterized as creep-crack-cut. The sliding surface is curved, but non-circular. A steep main scarp cuts through the hard rock in the upper part of the slope and forms the proximal part of the rupture surface, daylighting at the crown. The slide movement is roughly rotational around an axis that is parallel to the ground surface (Fig. 21).

According to international standards (WP/WLI, 1993), the type of the Sanmashan ancient slide should be classified as a successive rotational rock slide (Fig. 22), as we already concluded after our field survey (Fig. 13). This type of slide generally occurs as a result of river incision, in subhorizontal layered rock masses on a gently inclined slope with hard rock overlying soft rock. Other examples are the Chana landslide, Longyangxia along the Yellow River (Fig. 23) and the Yanchihe landslide in Hubei Province, China (Zhang and Huang, 1990).

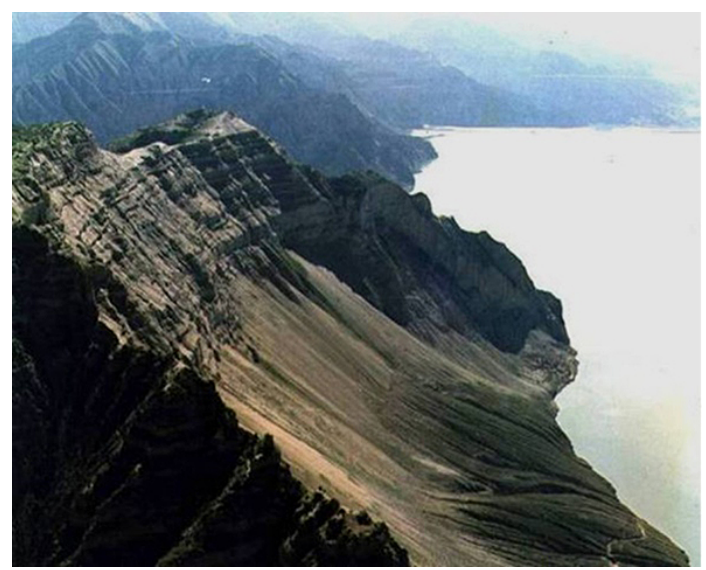

Figure 23. The Chana landslide, Longyangxia, China.

\section{Influence of seepage on the stability of the Sanmashan landslide}

On the basis of the results of the research described above, we analysed the influence of seepage on the stability of the Sanmashan landslide.

\subsection{Methodology}

\subsubsection{Modelling software and stability analysis}

We used the software Geo-Slope 2007 (Geo-Slope International Ltd., 2007). The variation of the groundwater level induced by the reservoir filling or rainfall and the related change in pore water pressure are simulated using the code SEEP/W. We carried out the limit equilibrium slope stability analysis with the software SLOPE/W. During the analysis, the output of the seepage simulation was used as input for the stability analysis, for which we adopted the Morgenstern and Price (1965) method to calculate the factor of safety (FOS).

\subsubsection{Model assumptions}

Three cross sections (Fig. 13) were chosen to conduct the two-dimensional combined seepage-slope stability analysis. For each cross section, five main hydrogeologicalgeomechanical units are identified.

(1) The upper unit of the slide mass is dense to very dense and contains grey or dark grey crushed stone in a matrix of silty clay and sand. The crushed stone is derived from limestone $\left(T_{2 \mathrm{~b}}^{3}\right)$. (2) The intermediate unit has a higher density, is reddish or dark red/brown in colour, and contains crushed stone in a matrix of clay and silty clay. The crushed stone is derived from mudstone and silty mudstone $\left(T_{2 \mathrm{~b}}^{2}\right)$. Units (3)(5) are the underlying stable and undeformed bedrock of the geological units $T_{2 \mathrm{~b}}^{3}, T_{2 \mathrm{~b}}^{2}$ and $T_{2 \mathrm{~b}}^{1}$. Each unit has been subdivided into a finite element mesh that combines triangular and quadrilateral elements of different sizes (Fig. 24). 


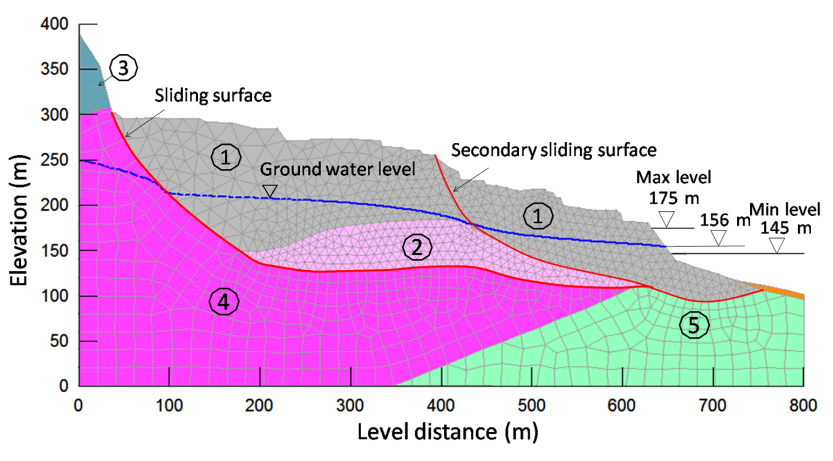

Figure 24. Model of the two-dimensional numerical stability analysis of the Sanmashan landslide (cross section I-I' in Fig. 12).

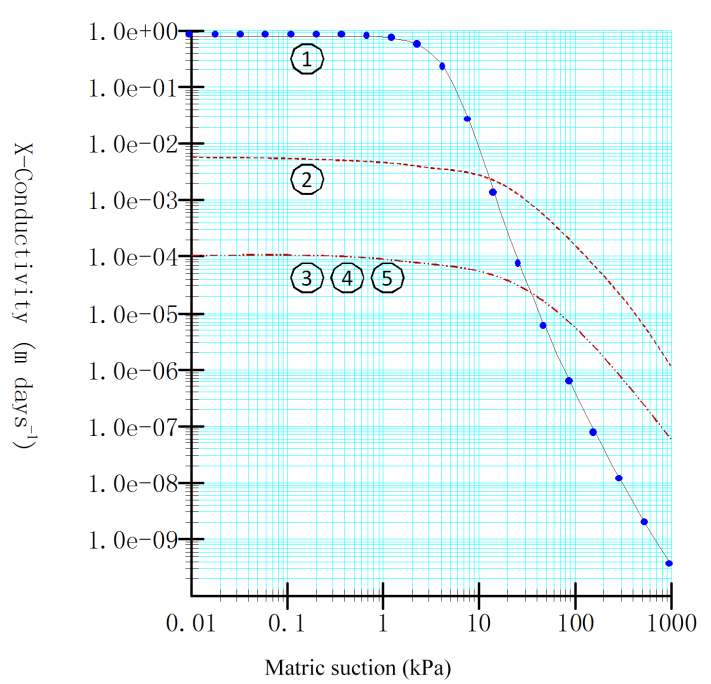

Figure 25. Hydraulic conductivity functions adopted for the main hydrogeological units: (1) $Q^{\text {del }}\left(T_{2 \mathrm{~b}}^{3}\right)$, (2) $Q^{\text {del }}\left(T_{2 \mathrm{~b}}^{2}\right)$, (3)(5) bedrock types $T_{2 \mathrm{~b}}^{3}, T_{2 \mathrm{~b}}^{2}$, and $T_{2 \mathrm{~b}}^{1}$.

The physical and mechanical parameters of the analytical model were determined according to the material testing results. The permeability of the different units is an important parameter affecting the stability analysis. We have carried out an inversion analysis on the data used in a previous study (Wang et al., 2013). The parameters of the model materials of stability analysis are listed in Table 1 . The hydraulic conductivity functions that we adopted for the main hydrogeological units are shown in Fig. 25.

\subsubsection{Historical reservoir level variations and rainfall data}

The repeated filling-drawdown cycles and rainfall are the main factors that affect the stability of the Sanmshan landslide (Zangerl et al., 2010; Paronuzzi et al., 2013; Galeandro et al., 2013). Based on a statistical analysis of the historical
Table 4. The water level fluctuation rates chosen for the fillingdrawdown cycles of the reservoir level (Stages A-H see Fig. 27).

\begin{tabular}{llrr}
\hline Stage & Time & $\begin{array}{r}\text { Reservoir } \\
\text { level }(\mathrm{m})\end{array}$ & $\begin{array}{r}\text { Average } \\
\text { fluctuation } \\
\text { rate } \\
\text { (m day }^{-1} \text { ) }\end{array}$ \\
\hline $\mathrm{AB}$ & 1 Jan-15 May & $175-160$ & -0.11 \\
$\mathrm{BC}$ & 15 May-10 Jun & $160-145$ & -0.58 \\
$\mathrm{CD}$ & 10 Jun-4 Jul & $145-145$ & 0.00 \\
$\mathrm{DE}$ & 4 Jul-29 Jul & $145-155$ & +0.40 \\
$\mathrm{EF}$ & 29 Jul-15 Aug & $155-145$ & -0.59 \\
$\mathrm{FG}$ & 15 Aug-18 Oct & $145-175$ & +0.47 \\
$\mathrm{GH}$ & 18 Oct-31 Dec & $175-175$ & 0.00 \\
\hline
\end{tabular}

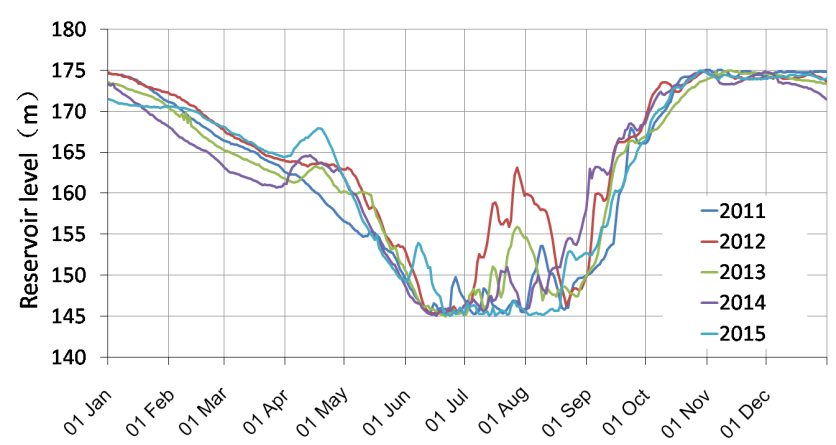

Figure 26. The reservoir level data from 2011 to 2015.

data, the reservoir level and rainfall values are determined, as follows.

Figure 17 shows that the reservoir level has varied annually between the elevations of 175 and $145 \mathrm{~m}$ since January 2011. Through the statistical analysis of the historical data from 2011 to 2015 of the reservoir level (Fig. 26), the annual fluctuation rate of the cycles is determined (Fig. 27 and Table 4). It was used for the boundary conditions in the numerical modelling.

The historical rainfall records of 1964-2013 for the new Fengjie town have been collected and analysed. The variation of average monthly rainfall during the years 1964-2013 shows that heavy rainfall is mainly concentrated in June and July (Fig. 28). Based on the probability statistics of the maximum daily rainfall (Table 5), the maximum rainfall intensity for different return periods has been calculated (Fig. 29 and Table 6). A daily rainfall of $140 \mathrm{~mm}$ in return periods of 50 years ( $2 \%$ probability) has been adopted as the boundary condition in numerical modelling. 
Table 5. Annual maximum rainfalls in the period 1964-2013.

\begin{tabular}{lrlrlr}
\hline Date & $\begin{array}{r}\text { Annual } \\
\text { maximum } \\
\text { rainfall }\end{array}$ & Date & $\begin{array}{r}\text { Annual } \\
\text { maximum } \\
\text { rainfall } \\
\left(\text { mm day }^{-1}\right)\end{array}$ & $\begin{array}{l}\text { Date } \\
\text { maximum }\end{array}$ & Annual \\
& & mm day $\left.^{-1}\right)$ & & $\begin{array}{r}\text { rainfall } \\
\left.\text { mm day }^{-1}\right)\end{array}$ \\
\hline 24 May 1964 & 121.40 & 25 Aug 1981 & 56.30 & 29 Jun 1998 & 141.30 \\
17 Aug 1965 & 88.60 & 8 Sep 1982 & 110.30 & 7 Jul 1999 & 161.40 \\
7 Oct 1966 & 37.70 & 6 Oct 1983 & 96.10 & 16 May 2000 & 79.70 \\
21 Jul 1967 & 70.10 & 13 Jun 1984 & 113.20 & 12 Jul 2001 & 100.80 \\
14 Sep 1968 & 71.90 & 21 Jun 1985 & 95.90 & 21 Sep 2002 & 73.20 \\
5 May 1969 & 108.80 & 15 Jun 1986 & 96.00 & 19 Jul 2003 & 72.20 \\
28 May 1970 & 84.10 & 14 Sep 1987 & 52.20 & 20 Sep 2004 & 86.80 \\
3 May 1971 & 97.80 & 8 May 1988 & 81.90 & 28 Aug 2005 & 82.40 \\
21 Jun 1972 & 57.50 & 11 Jul 1989 & 127.90 & 5 Jul 2006 & 75.10 \\
10 Sep 1973 & 66.90 & 1 Jul 1990 & 65.50 & 30 Jul 2007 & 66.80 \\
5 Aug 1974 & 45.70 & 30 Jun 1991 & 70.40 & 20 Jun 2008 & 81.70 \\
26 Jun 1975 & 103.20 & 11 May 1992 & 77.00 & 29 Aug 2009 & 93.80 \\
21 Jul 1976 & 56.70 & 18 Jul 1993 & 88.50 & 7 Jun 2010 & 49.20 \\
4 Oct 1977 & 50.10 & 25 Jun 1994 & 91.30 & 23 Jun 2011 & 95.10 \\
24 Jun 1978 & 71.90 & 25 Jul 1995 & 69.50 & 5 Jul 2012 & 60.30 \\
12 Sep 1979 & 106.70 & 28 Aug 1996 & 63.10 & 25 May 2013 & 56.90 \\
31 May 1980 & 71.30 & 5 Jul 1997 & 49.70 & & \\
\hline
\end{tabular}

Table 6. The maximum rainfall intensity for different return periods.

\begin{tabular}{lccccc}
\hline Frequency/probability (\%) & $20 \%$ & $10 \%$ & $5 \%$ & $2 \%$ & $1 \%$ \\
\hline Return periods (years) & 5 & 10 & 20 & 50 & 100 \\
Rainfall intensity (mm day $^{-1}$ ) & 101 & 115 & 126 & 140 & 151 \\
\hline
\end{tabular}

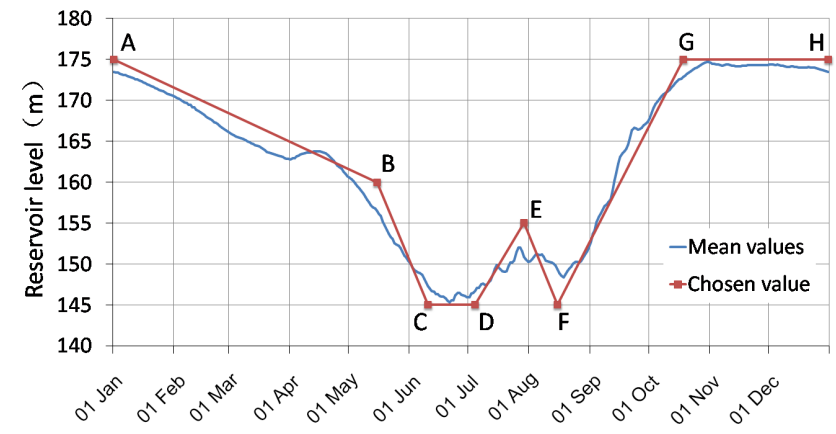

Figure 27. The mean values of the reservoir level during the fillingdrawdown cycles in 2011-2015. The chosen values for the analysis (see also Table 5).

\subsection{Stability analysis}

\subsubsection{Factor of safety (FOS) variations induced by reservoir filling-drawdown cycles}

With a drawdown of the reservoir level from 175 to $145 \mathrm{~m}$ (Fig. 27), the delay in the lowering of the groundwater level

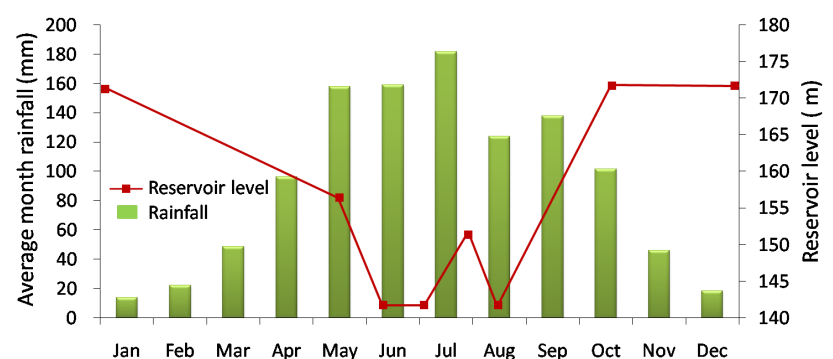

Figure 28. The average monthly rainfall from 1964 to 2013 and the chosen value of the filling-drawdown cycles of the reservoir level for the numerical stability analysis.

after the lowering of the reservoir water level will cause a decrease in the landslide stability. After stabilization of the reservoir water level at $145 \mathrm{~m}$, further lowering of the groundwater level in the sliding body will gradually lead to an increase in the stability of the landslide (Figs. 30 and 31).

During a rise in the reservoir water level from 145 to $175 \mathrm{~m}$ (Fig. 27), the stability of the landslide will increase as the rise in the groundwater level in the slide mass lags behind the rise of the reservoir water level. After reaching the reservoir water level of $175 \mathrm{~m}$, the stability of the landslide will again gradually decrease with a further rise of the groundwater level (Figs. 30 and 32).

Due to the filling-drawdown cycles of the Three Gorges Reservoir (Fig. 27), but without the rainfall effects, the minimum stability coefficient (FOS) of the Sanmashan landslide is 1.617 , and that of the partial landslide at the front is 1.114 . 


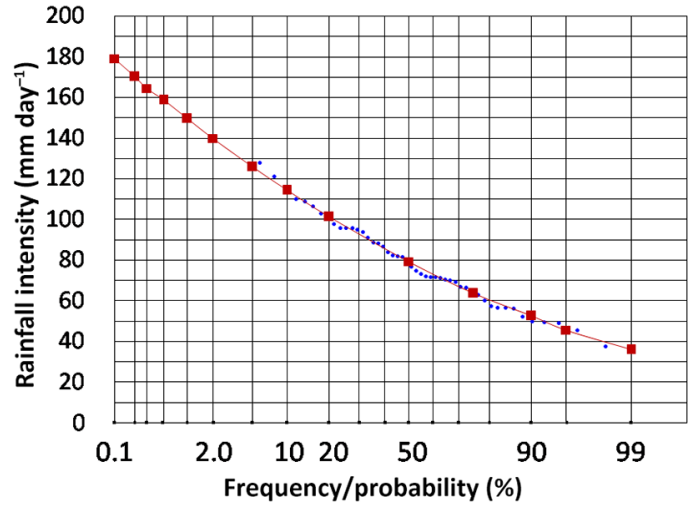

Figure 29. Maximum rainfall intensity in $\mathrm{mm} \mathrm{day}^{-1}$ for different return periods.

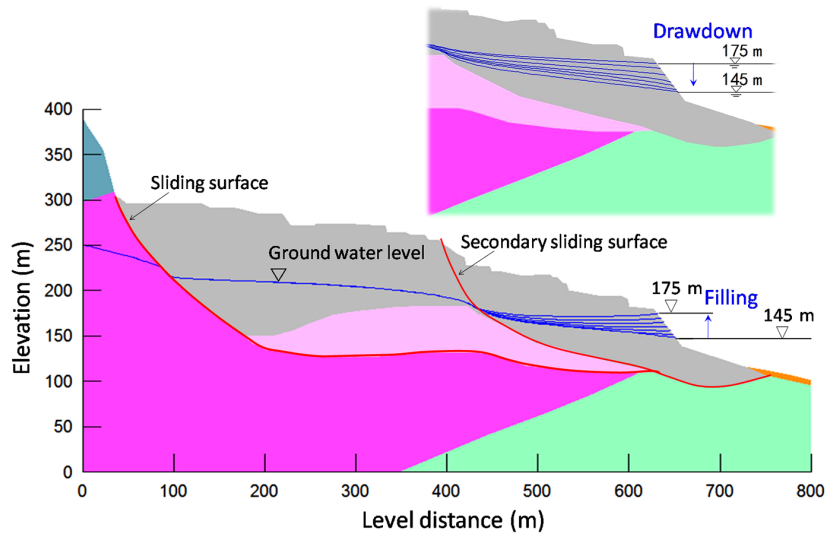

Figure 30. Ground water level changes during the fillingdrawdown cycles of the Three Gorges Reservoir.

\subsubsection{Rainfall influence on the Sanmashan landslide stability}

A daily rainfall of $140 \mathrm{~mm}$ in return periods of 50 years $(2 \%$ probability), during a period of reservoir water level drawdown from 175 to $145 \mathrm{~m}$, has little effect on the stability of the whole landslide (decrease in FOS of $2.4 \%$ ), but has a large influence on the secondary partial landslides at the front (decrease in FOS of $4.2 \%$ ) (Fig. 32).

During rainfall and filling-drawdown cycles in the Three Gorges Reservoir, the minimum stability coefficient (FOS) of the Sanmashan landslide is 1.578 and of the partial landslide at the front it is 1.067 .

\section{Conclusions}

Extensive field studies and mapping, deep borehole drilling, investigation of the already existing tunnels and a large foundation excavation pit as well as centrifuge model testing and numerical stability analysis were carried out to investigate

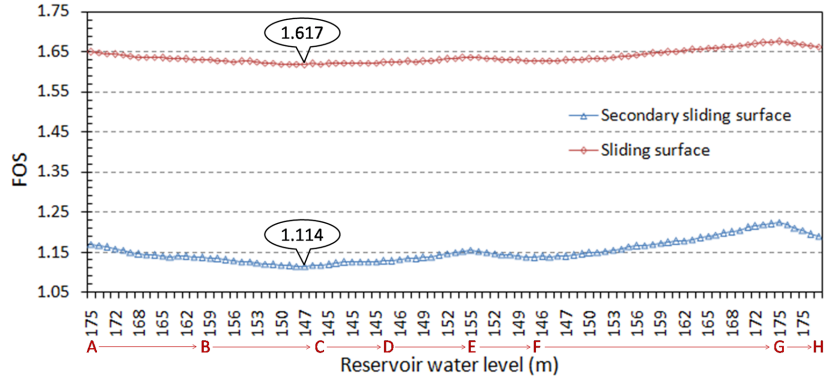

Figure 31. Factor of safety (FOS) variation during the fillingdrawdown cycles of the Three Gorges Reservoir (Points A-H see Fig. 27).

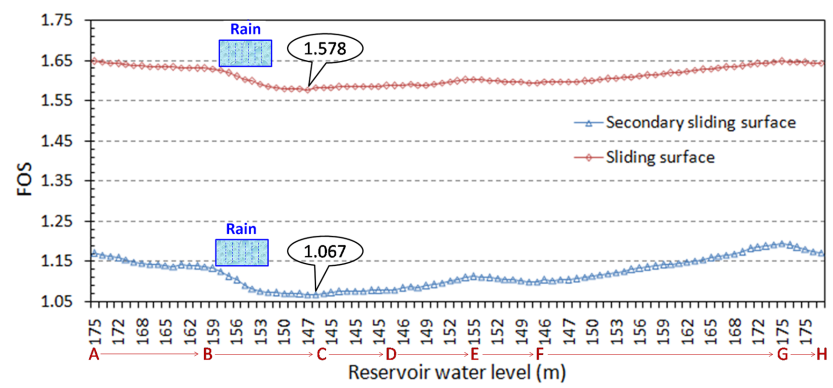

Figure 32. Factor of safety (FOS) variation due to rainfall and filling-drawdown cycles of the Three Gorges Reservoir (Points AH see Fig. 27).

the stability of a deep-seated ancient rock slide in the Three Gorges Reservoir area.

Three tectonic units, the upper Yangtze platform fold belt, the marginal depression of the Sichuan Basin, and the Dabashan platform fold belt, converge on this region. In the new Fengjie town, the site of the landslide, a N-S compressive geostress field is the tectonic background. For this reason we discarded the theory that the deformations in the slope were related to a fault graben, as that would have needed a tensional geostress field. Our investigations have also shown that the four normal faults, which in earlier studies were used to support the hypothesis of a fault graben, share some common characteristics, which do not support the local fault graben theory. Thus we come to the conclusion that a local fault graben does not explain the presence of the large-scale weak layer in the Sanmashan area.

Meanwhile, there are numerous unique geological features and interesting slickenside relics of the ancient slide discovered in the field. From the structural geological evidence, geomorphological evidence and slickenside traces, we conclude that this area is a huge deep-seated ancient rock slide, called the Sanmashan landslide.

A steep cliff over $130 \mathrm{~m}$ in height forms the back scarp of the Sanmashan landslide. Two gullies, Baiyangping as a western and Sunjia as an eastern boundary, as well as the Yangtze River in the front, form the boundaries of the 
landslide. The terrain slope angle of the landslide is $15-$ $20^{\circ}$. The length of the landslide is over $780 \mathrm{~m}$, the width is about $1020 \mathrm{~m}$, the maximum thickness is over $150 \mathrm{~m}$, the average thickness is about $125 \mathrm{~m}$, and the volume is about 100 million $\mathrm{m}^{3}$. The Sanmashan landslide can be subdivided into four domains based on differences in morphology, geological structure, and inferred failure mechanics. There are three secondary landslides at the foot of the Sanmashan landslide called the Houzishi, Zhiwuyou, and Laofangzi landslides. There was a sign of a partial reactivation of one of the secondary landslides in October 2006 and October 2008 at the moment of reservoir filling, but after May 2009 none of the GPS monitored displacements of the landslide showed any further increase. This suggests that the Sanmashan landslide is presently inactive without the likelihood of reactivation by fluctuations of the reservoir water or rainfall.

The original surface of the ancient slide was a gently inclined slope consisting of limestone of $T_{2 \mathrm{~b}}^{3}$ in its upper part and mudstone and siltstone of $T_{2 \mathrm{~b}}^{2}$ in its lower part. It is a hard-on-soft rock slope, which provides a basis for the sliding, while the free face is provided by the downcutting of the Yangtze River. These factors finally led to the formation of the Sanmashan ancient slide. The formation process of the ancient slide was demonstrated in a large geotechnical centrifuge model test, which showed a deformation and failure process of creep-crack-cut. The ancient slide can be characterized as successive rotational rock slide.

Finally, the combined analysis of seepage and slope stability of the Sanmashan landslide has been carried out, the results of which show that during rainfall and reservoir fillingdrawdown cycles the Sanmashan landslide as a whole is stable and dormant, while the secondary (partial) landslides in the toe area are basically stable but can be reactivated. This research provides an important guidance for strict land use planning in the sliding zone.

\section{The Supplement related to this article is available online at doi:10.5194/nhess-16-1719-2016-supplement.}

Acknowledgements. This research was financially supported by the National Basic Research Program of China (No. 2013CB733202), the Key Project of TGR (No. SXKY3-1-1-200901), and the State Key Laboratory of Geohazard Prevention and Geoenvironment Protection (No. SKLGP2015Z008). The authors sincerely thank Xuebin Huang, Wenming Cheng, and Kaixiang Xu for their assistance. Wei Zhang, Ruihua Xiao, Lei Zhang, and others contributed to the investigation and drilling. Guang Zheng and Kai Wang contributed the centrifuge model testing. Fan Yang and Yangjian Cao contributed the stability analysis. The manuscript was directed by Zhuoyuan Zhang and Guangzong Peng. The authors wish to thank the anonymous referees for their helpful suggestions and constructive comments, which have contributed greatly in improving the quality of the manuscript.
Edited by: T. Glade

Reviewed by: C. Xu and two anonymous referees

\section{References}

Alonso, E. E. and Pinyol, N. M.: Criteria for rapid sliding I. A review of Vaiont case, Eng. Geol., 114, 198-210, 2010.

Barla, G., Antolini, F., Barla, M., Mensi, E., and Piovano, G.: Monitoring of the Beauregard landslide (Aosta valley, Italy) using advance and conventional techniques, Eng. Geol., 116, 218-235, 2010.

BIS-CWRC - Bureau of Investigation and Survey, Changjiang Water Resource Commission: The geology argument report of the relocation site of the Fengjie County in Three Gorges Reservoir (Detailed investigation stage), Wuhan, 1997.

BIS-CWRC - Bureau of Investigation and Survey, Changjiang Water Resource Commission: Engineering Geology Investigation Report of protecting project of bank slopes of the new Fengjie County (feasibility study stage), Wuhan, 1999.

Brideau, M., Yan, M., and Stead, D.: The role of tectonic damage and brittle rock fracture in the development of large rock slope failures, Geomorphology, 103, 30-49, 2009.

Chang, W. Y., Li, Y. H., Ma, F. C., and Zhong, J. Y.: On the mechanical mechanism of the formation of graben, Chin. Scient. Geol. Sin., 1, 1-11, 1981.

Chen, M. S. and Zhang, S. H.: Characteristics and forming mechanism of opposite protruding arcuate structural zones in the Three Gorges Area of the Yangtze river, south China, Geol. Miner. Resour. S. China, 1, 48-55, 1998.

Crosta, G. B.: Landslide, spreading, deep-seated gravitational deformation: Analysis, examples, problems and proposals, Geograf. Fis. Dinam. Quatern., 19, 297-313, 1996.

Crosta, G. B. and Zanchi, A.: Deep-seated slope deformations: Huge, extraordinary, enigmatic phenomena, in: Landslides in Research, Theory and Practice, edited by: Bromhead, E., Dixon, N., and Ibsen, M. L., Thomas Telford, London, 351-358, 2000.

Cruden, D. M. and Martin, C. D.: Before the Frank Slide, Can. Geotech. J., 44, 765-780, 2007.

Cruden, D. M. and Varnes, D. J.: Landslide types and processes, in: Landslides investigation and mitigation, Transportation research board, chap. 3, Special Report 247, edited by: Turner, A. K. and Schuster, R. L., US National Research Council, Washington, D.C., 36-75, 1996.

Galeandro, A., Doglioni, A., Guerricchio, A., and Simeone, V.: Hydraulic stream network conditioning by a tectonically induced, giant, deep-seated landslide along the front of the Apennine chain (south Italy), Nat. Hazards Earth Syst. Sci., 13, 1269-1283, doi:10.5194/nhess-13-1269-2013, 2013.

Geo-Slope International Ltd.: Seepage and stability modeling with SEEP/W and SLOPE/W, Users Manuals, Calgary, Alberta, Canada, 2007.

Huang, R. Q.: Mechanisms of large-scale landslides in China, Bull. Eng. Geol. Environ., 71, 161-170, 2012.

Hungr, O., Leroueil, S., Picarelli, L.: The Varnes classification of landslide types, an update, Landslides, 11, 167-194, 2014.

Illies, J. H.: Mechanism of garben formation, Tectonophysics, 73, 249-266, 1981. 
John, J. C. and Douglas, S.: Landslides: Types, Mechanisms and Modeling, Cambridge University Press, Cambridge, 2012.

Li, H. L., Yi, S. H., and Deng, Q. L.: Development characteristics and their spatial variations of Badong formation in the Three Gorges Reservoir Region, J. Eng. Geol., 14, 578-581, 2006.

Li, H. Z., Zhou, Y., and Pan, Y. Z.: The stability analysis and protection measures of the Houzishi landslides in the Three Gorges Reservoir Region, Hubei Geol. Miner. Resour., 16, 97104, 2002.

Li, J. J., Xie, S. Y., and Kuang M. S.: Geomorphic evolution of the Yangtze Gorges and the time of their formation, Geomorphology, 41, 125-135, 2001.

Michael, W. H., Phillip, J. S., and Gregory, T. F.: When Landslides are Misinterpreted as Faults: Case Studies from the Western United States, Environ. Eng. Geosci., 11, 313-325, 2012.

Morgenstern, N. R. and Price, V. E.: The analysis of the stability of general slip surfaces, Geotechnique, 15, 79-93, 1965.

Nakajima, H. and Stadler, A. T.: Centrifuge modeling of onestep outflow tests for unsaturated parameter estimations, Hydrol. Earth Syst. Sci., 10, 715-729, doi:10.5194/hess-10-715-2006, 2006.

Nanjiang Geological Team: Investigation report of Sanmashan landslide in New Fengjie Town, Chongqing, 1999.

No. 107 Geological Team of Sichuan Province: $1: 200000$ the regional geological report of Fengjie, China University of Geosciences, Wuhan, 37-39, 1980.

Paronuzzi, P., Rigo, E., and Bolla, A.: Influence of filling-drawdown cycles of the Vajont reservoir on Mt. Toc slope stability, Geomorphology, 191, 75-93, 2013.

Qi, S. W., Wu, F. Q., Yue, Z. Q., and Liu, C. L.: Characteristics and mechanism of deep weathering of argillaceous limestones at Fengjie County, Three Gorges Region, Central China, Bull. Eng. Geol. Environ., 71, 285-295, 2012.

Tang, M. G., Xu, Q., and Huang, R. Q.: Site monitoring of suction and temporary pore water pressure in an ancient landslide in the Three Gorges reservoir area, China, Environ. Earth Sci., 73, 5601-5609, 2015a.
Tang, M. G., Xu, Q., Huang, X. B., Xu, K. X., Cheng, W. M., and Wang, K.: Recognition and Genetic Mechanism of Sanmashan Deep-Seated Landslide, Three Gorges Reservoir Area, China, in: Engineering Geology for Society and Territory - Volume 2: Landslide Processes, edited by: Lollino, G., Giordan, D., Crosta, G. B., Corominas, J., Azzam, R., Wasowski, J., and Sciarra, N., Springer International Publishing, Switzerland, 587-591, 2015b.

Taylor, R. N.: Centrifuges in Modeling: Principles and Scale Effects, in: Geotechnical Centrifuges Technology, edited by: Taylor, R. N., Blackie Academic \& Professional, London, 19-33, 1995.

Varnes, D. J.: Slope movement types and processes, in: Landslides Analysis and control, Special Report 176, edited by: Schuster, R. L. and Krizek, R. J., National Research Council, Transportation Research Board, Washington, D.C., 11-33, 1978.

Wang, J. G., Zhou, Y., and Huang, Z. P.: Groundwater analyses of Houzishi landslide in the Three Gorges Reservoir, J. Rock Mech. Eng., 25, 2757-2762, 2006.

Wang, K., Tang, M. G., and Xu, Q.: Study on the Inversion Method of Selecting Seepage Parameter for Sanma Mountain Landslide, Yellow River, 35, 124-126, 2013.

WP/WLI - International Geotechnical Society's UNESCO Working Party on World Landslide Inventory: A multi-lingual landslide glossary, Bitech Publishers, Vancouver, 51-58, 1993.

Yang, D. Y.: Genetic mechanism of the alluvial terraces along the Three Gorges course of the Changjiang River, Acta Geogr. Sin. 42, 120-126, 1988.

Zangerl, C., Eberhartd, E., and Perzlmaier, S.: Kinematic behaviour and velocity characteristics of a complex deep-seated crystalline rockslide system in relation to its interaction with a dam reservoir, Eng. Geol., 112, 53-67, 2010.

Zhang, Z. Y. and Huang, R. Q.: Epigenetic recreation of rockmass structure and time-dependent deformation, in: Proc. of the 6th Congress of IAEG, A. A. Balkema, Rotterdam, the Netherlands, 2065-2072, 1990. 